Research Division

Federal Reserve Bank of St. Louis

Working Paper Series

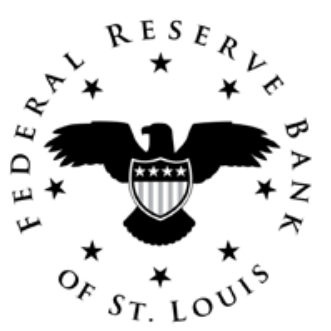

Credit Markets, Limited Commitment, and Government Debt

\author{
Francesca Carapella \\ and \\ Stephen D. Williamson
}

Working Paper 2014-010A

http://research.stlouisfed.org/wp/2014/2014-010.pdf

March 2014

FEDERAL RESERVE BANK OF ST. LOUIS

Research Division

P.O. Box 442

St. Louis, MO 63166

\footnotetext{
The views expressed are those of the individual authors and do not necessarily reflect official positions of the Federal Reserve Bank of St. Louis, the Federal Reserve System, or the Board of Governors.

Federal Reserve Bank of St. Louis Working Papers are preliminary materials circulated to stimulate discussion and critical comment. References in publications to Federal Reserve Bank of St. Louis Working Papers (other than an acknowledgment that the writer has had access to unpublished material) should be cleared with the author or authors.
} 


\title{
Credit Markets, Limited Commitment, and Government Debt*
}

\author{
Francesca Carapella \\ Board of Governors of the Federal Reserve System \\ Stephen Williamson \\ Department of Economics, Washington University in St. Louis \\ Federal Reseve Bank of St. Louis
}

February 24, 2014

\begin{abstract}
A dynamic model with credit under limited commitment is constructed, in which limited memory can weaken the effects of punishment for default. This creates an endogenous role for government debt in credit markets, and the economy can be non-Ricardian. Default can occur in equilibrium, and government debt essentially plays a role as collateral and thus improves borrowers' incentives. The provision of government debt acts to discourage default, whether default occurs in equilibrium or not.
\end{abstract}

\footnotetext{
*These are our own views, and not necessarily those of the Federal Reserve Banks of Richmond and St. Louis, or the Board of Governors of the Federal Reserve System. We thank seminar and conference participants at the Chicago Federal Reserve Bank Workshop on Money, Banking, and Payments, the 2012 SED Meetings, along with 3 anonymous referees and the editor Dimitri Vayanos, for their helpful comments and suggestions.
} 


\section{Introduction}

Why does government debt matter? There is a rich and varied literature which delivers a number of different answers to that question. For example, government debt can be part of a mechanism for effecting intergenerational transfers; it can permit the relaxation of credit constraints for private sector economic agents; it can provide a medium for self-insurance in the context of incomplete insurance markets; and it can permit the smoothing of tax distortions over time. In this paper, we explore a novel mechanism by which government debt might act to improve economic welfare. In particular, with limited commitment and imperfect information flows, government debt can play an important role in disciplining credit market behavior. This role arises in contexts where default in credit markets is only a threat and, alternatively, where default occurs in equilibrium. Our model gives some insight into the role of government debt as collateral, and has implications for financial crisis phenomena.

Diamond (1965) shows how government debt, supported by taxation, can effect appropriate intergenerational transfers and support efficient capital accumulation. Woodford (1990) and Kiyotaki and Moore (2008) study the role of government debt in relaxing private credit and liquidity constraints in incomplete markets environments, while Aiyagari and McGrattan (1998) examine some quantitative issues in a related economic environment which also includes tax distortions. Holmstrom and Tirole (1998) explore related issues to Woodford (1990), but in a model with explicit limited commitment.

Woodford (1990) and Holmstrom and Tirole (1998) both study environments in which the government is endowed with an advantage in credit markets. In particular, these researchers assume that, while private economic agents are credit constrained either for exogenous reasons (as in Woodford 1990) or because of limited commitment (as in Holmstrom and Tirole 1998), there is no problem for the government in getting the same private economic agents to pay their taxes. While it may be true in reality that governments have some advantages over private sector agents in collecting on debts, our analysis begins by leveling the playing field. We assume that the government has no special advantage in collecting on debts owed to it, relative to private sector creditors. This will help to make clear our departure from the existing literature.

Monetary theorists have explored some of the consequences of the symmetric treatment of default on public and private liabilities. A key idea in modern monetary economics, emphasized by Kocherlakota (1998), is that "money is memory," in that limited recordkeeping is the key friction that explains a role for public liquidity. Indeed, Sanches and Williamson (2010) show, in part using some ideas from Andolfatto (2011), how an economy with no memory, monetary exchange, and an optimal monetary policy achieves the same equilibrium allocation as an economy with perfect memory and private credit, in which money is not valued. An important element in that argument is limited commitment, which restricts private credit, and also restricts the government's ability to tax private economic agents. Gu and Wright (2011), and Gu, Mattesini and Wright (2013) also explore issues of money and credit in related models. The flow of 
information - i.e. the extent of "memory" - will be key to our results, so in this sense we are using insights from the monetary literature to help understand the role played by public liquidity in a broader sense. However, an important point to note at the outset is that the role we have in mind for public debt cannot be filled by an anonymously-traded asset such as currency.

This paper makes three key contributions. First, we show how, when incentive constraints arising from limited commitment bind, government debt can act to relax these, increasing the quantity of exchange and economic welfare. Government debt can act to make default more costly, and this effect acts to relax incentive constraints. One can interpret this as a role for government debt as collateral in credit contracts.

In acquiring government debt to secure a credit contract, the potential costs of default are transferred from private lenders to the government. In spite of the fact that we assume in our model that the government is no better at collecting on its tax liabilities than private lenders are at collecting on their debts, this transfer acts to increase trade in equilibrium and to increase social welfare. The key mechanism works in part through the punishment for defaulting induced by the cost of having to acquire government debt in order to trade.

Second, in our model borrowers may default in equilibrium. Typically, in models with limited commitment, for example Kehoe and Levine (1993), Kocherlakota (1996), or Sanches and Williamson (2010), there is only potential default. In equilibrium in this class of models, credit is typically supported by the threat of off-equilibrium punishments in the event of default, and default does not occur in equilibrium. This is of course problematic if we want to use these models to address quantitative phenomena. The existence of default, and regularities in default behavior are features that we would like to explain. In our model, we exploit limited memory/recordkeeping, in order to support default in equilibrium. Default occurs in equilibrium in costly state verification models (see Townsend 1979), but those are static constructs. In our model, it is assumed that lenders sometimes do not have access to a would-be borrower's credit history. Thus, it may be the case that a lender faces an adverse selection problem - he or she cannot tell the difference between a would-be borrower who has defaulted in the past, and one who has not. In equilibrium, among a group of identical borrowers, some may default while others do not. Those who default have nothing to lose from defaulting, as lenders who know their credit history will not lend to them in the future. However, some borrowers have enough to lose from defaulting that they will never do it. Effectively, default behavior is a self-fulfilling phenomenon. In equilibrium lenders charge borrowers a default premium when these lenders know that some borrowers will default, and non-defaulting borrowers are willing to pay a higher interest rate. This happens because the marginal benefit of additional consumption exceeds the higher marginal cost of loan repayment.

Third, when there is default in equilibrium there is an additional role for government debt in exchange. If would-be borrowers can exchange government debt rather than engage in credit contracts, this can eliminate the adverse selection problem, though it need not eliminate default, as agents can still default on their 
tax liabilities. This can be interpreted as another role for collateral. Private lenders who have no access to credit histories can require that government debt be posted to secure credit contracts, and this generates more exchange, even if incentive constraints are not binding in the absence of government debt. The economic mechanism works through the distribution of the losses from default, using tax collection and the issue of government debt. ${ }^{1}$ Thus, government debt can also act to eliminate default by ruling out equilibria with a large number of defaulting borrowers.

In this model Ricardian equivalence does not hold, in general, since changing the quantity of government debt in existence matters for the equilibrium allocation. However, the extent to which Ricardian equivalence is violated depends on the equilibrium behavior of the economic agents in the model. In an equilibrium where there are global punishments, in that all economic agents are punished should any individual default, Ricardian equivalence holds. In such an equilibrium, changing the quantity of government debt has no consequences. However, in an equilibrium with individual punishments - only a borrower who defaults is punished for his or her bad behavior - government debt matters in general, though for some parameter values Ricardian equivalence will always hold. In particular, if the discount factor is sufficiently high (so that economic agents care sufficiently about losing future access to credit markets) and if access to credit histories by lenders is sufficiently good, then government debt is neutral.

The basic model we work with is closely related to the one in Sanches and Williamson (2010), which in turn builds on Lagos and Wright (2005) and Rocheteau and Wright (2005). The Lagos-Wright (2005) structure, which incorporates centralized markets and decentralized trade, makes it convenient to integrate market trade in government debt with a strategic approach in a dynamic setting. A structure for incorporating strategic behavior is useful for handling aspects of the limited commitment problem. Sanches-Williamson (2010) focuses exclusively on the interaction between money and credit, and on monetary policy, while our interest in this paper is on the implications of government debt policy for default behavior and exchange. This model is potentially of interest for explaining behavior that we observe during financial crises. In particular, there can be an endogenous breakdown in credit relationships in the model, in that default behavior can be a self-fulfilling phenomenon. There can be equilibria in which lenders will not lend to particular borrowers because those borrowers are expected to default, and they do indeed default, because of their limited access to credit markets. The exchange of government debt can mitigate or eliminate this problem.

A key feature of our analysis is that, for government liquidity to play a welfare-improving role, it is important that this asset have good properties as collateral. Government debt is good collateral in the model because it assures payment to the lender, while providing incentives for the borrower. Payment is assured by what is effectively loss mutualization, working through the tax

\footnotetext{
${ }^{1}$ Taxes are incentive compatible (non-defaulting borrowers are willing to pay them) and the demand for government debt stems from the need to acquire collateral to secure loans.
} 
system. From a lender's point of view, government debt posted as collateral or offered in exchange is a safe asset, in spite of the fact that some economic agents may default on the taxes that support the government debt arrangement. Thus, the lender does not need to know whether the borrower will pay or default, and the adverse selection problem is solved. As well, government debt in the model is easy to seize and costly to acquire, which gives the borrower the appropriate incentives. It is thus important in the model that government liquidity cannot be held anonymously and cannot be hidden from the government, unlike currency. Kocherlakota (2003) shows how illiquid bonds could add a richer structure to an economy with limited recordkeeping, and thus provide better risk sharing, which is quite different from what we capture here. As well, Freeman (1996) is an environment where fiat currency is useful in supporting efficient credit arrangements. In our model, we require more from government liquidity than basic medium-of-exchange properties: it must be good collateral.

The paper proceeds as follows. The model is constructed in the second section. In the third section, the properties of equilibria with global punishments are studied. Then symmetric equilibria with individual punishments, and asymmetric equilibria with individual punishments, respectively, are examined in Sections four and five. Finally, Section six concludes.

\section{The Baseline Model of Private Credit}

The baseline model we build on is a version of Lagos and Wright (2005), or Rocheteau and Wright (2005). Most often, models of this type are used to address issues in monetary economics, but more recently they have also proven useful in the study of credit economies with limited commitment, for example in Sanches and Williamson (2010) or Gu and Wright (2011). Some of our ideas will indeed make use of key results from the monetary economics literature, and those ideas can have a monetary interpretation, but our attention will be focused on the role of government liquidity, in the context of credit market frictions, rather than on government-provided money, narrowly defined.

Time is indexed by $t=1,2,3, \ldots$, and each period consists of two subperiods, in which trade occurs, respectively, in a centralized market $(C M)$ and a decentralized market $(D M)$. There is a continuum of agents with mass 2 , half of whom are buyers, with the other half being sellers. Each buyer has preferences given by

$$
E_{0} \sum_{t=0}^{\infty} \beta^{t}\left[-H_{t}+u\left(x_{t}\right)\right]
$$

where $H_{t}$ is labor supply minus consumption during the $C M, x_{t}$ is consumption in the $D M$, and $0<\beta<1$. Assume that $u(\cdot)$ is strictly concave, strictly increasing, and twice continuously differentiable with $u(0)=0, u^{\prime}(0)=\infty$, 


$$
\begin{gathered}
u^{\prime}(\infty)=0 \text {, and }-\frac{x u^{\prime \prime}(x)}{u^{\prime}(x)}<1 \text {. A seller has preferences given by } \\
\qquad E_{0} \sum_{t=0}^{\infty} \beta^{t}\left(X_{t}-h_{t}\right),
\end{gathered}
$$

where $X_{t}$ is consumption in the $C M$, and $h_{t}$ is labor supply in the $D M$. Buyers can produce only in the $C M$, and sellers produce only in the $D M$. When productive, an agent has access to a technology which permits the production of one unit of the perishable consumption good for each unit of labor input.

During the $D M$, each buyer is randomly matched with a seller. A fraction $\rho$ of $D M$ meetings are limited-information meetings, where the seller does not have access to the buyer's history. Even though there is limited information in this sense, the interaction between the buyer and seller in the meeting will be publicly recorded. The remaining fraction $1-\rho$ of $D M$ meetings are full-information meetings, where the seller has access to the public record and the interaction between buyer and seller is recorded. Thus, the key assumption about "memory" (see Kocherlakota 1998) in the model is that agents engaged in exchange may sometimes not have access to the public record, but all information that could possibly be useful for any agent living in this world always resides in the public record. Note that the public record includes information on whether meetings in the $D M$ were limited information or full information meetings. Credit histories are perfect, but a would-be lender may not have access to credit histories.

Another key credit friction, in addition to imperfect recordkeeping, is limited commitment (Kehoe-Levine 1993, Kocherlakota 1996, Sanches-Williamson 2010), in that economic agents in the model cannot be forced to work. Thus, a private debt will be repaid only if it is in the debtor's interest to do so.

In a $D M$ meeting between a buyer and a seller, the buyer makes a takeit-or-leave it offer to the seller. In this baseline credit model, this take-it-orleave-it offer will be a credit contract, involving goods produced by the seller and given to the buyer in the current $D M$, in exchange for a promise by the buyer to supply goods to the seller in the next $C M$. The nature of that contract will depend on the information available to the seller - whether the meeting is limited-information or full-information- and what the buyer stands to lose if he or she should default on the credit contract.

For readers who are unfamiliar with the Lagos-Wright (2005) structure, in this credit market context, the nature of heterogeneity among agents provides us with a simple motive for intertemporal exchange and credit contracts. Random matching in the $D M$ is helpful, as this permits the coexistence of credit arrangements with poor information and with good information about credit histories, respectively. This will play an important role in the analysis. Finally, quasilinear preferences for buyers eliminates wealth effects, and makes the $C M$ a period when debts are settled and the problem restarts. This gives some elements of decisionmaking a two-period structure, while maintaining an infinite horizon - the latter being critical for supporting the credit arrangements. Linear preferences for sellers, combined with take-it-or-leave-it offers by buyers in 
the $D M$ imply that behavior by sellers is trivial, simplifying our analysis by allowing us to focus on the behavior of buyers.

As a visual aid, Figure 1 shows the sequence of activities during a period in the model.

[Figure 1 here.]

\subsection{Symmetric Stationary Equilibria with Global Punish- ments}

We will first analyze equilibria that are symmetric and stationary, in that each buyer and each seller receive the same allocation, and consume the same amount in each period. Typically, in models with limited commitment, credit is supported by the threat of punishment for default. This punishment never occurs in equilibrium, but agents have equilibrium beliefs about how that punishment occurs - off equilibrium. As a benchmark, we start by considering equilibria supported by off-equilibrium-path global punishments, in which all economic agents are punished for the bad behavior of any one agent. This is a valid equilibrium to be considering, within the economic environment at hand, though global punishments have unrealistic features. In later sections we will consider symmetric equilibria with more realistic individual punishments, along with asymmetric equilibria in which some economic agents default in equilibrium.

In the equilibria under consideration, because the buyer will face global punishment in the event of default, and because default enters the public record whether a buyer is defaulting on a limited-information or full-information contract, the contracts will be the same in all $D M$ meetings. Therefore, in any $D M$ meeting, the buyer makes a take-it-or-leave-it offer $\left(x, \frac{x}{\beta}\right)$, where $x$ is the quantity of goods the seller produces in the $D M$ for the buyer, and $\frac{x}{\beta}$ is the quantity of goods the buyer produces for the seller in the next $C M$. This offer makes the seller indifferent to accepting. Then, letting $v$ denote the continuation value (constant for all $t$ ) for a buyer at the end of the $C M$, and $\hat{v}$ the punishment continuation value, $v$ is determined by

$$
v=\max _{x}[u(x)-x+\beta v]
$$

subject to

$$
x \leq \beta(v-\hat{v}) .
$$

Inequality (4) is an incentive constraint which states that, given limited commitment, the buyer must have the incentive to repay the loan during the $C M$ rather than facing punishment by the market, represented by the continuation value $\hat{v}$.

Since no one can be forced to work, the worst possible punishment is $\hat{v}=0$, i.e. perpetual autarky. Here $\hat{v}=0$ is accomplished off-equilibrium with global punishments. If any buyer defaults then this triggers global autarky. Note that global autarky is also an equilibrium, since if $\hat{v}=0$ then $v=x=0$ solves the 
problem (3) subject to (4). Thus, if any individual defaults, this is observed by everyone at the beginning of the $C M$. On the off-equilibrium path triggered by a default, each seller strictly prefers not to trade, as the belief that any buyer who receives a loan will default is self-fulfilling on the off-equilibrium path.

\subsubsection{Incentive Constraint Does Not Bind}

To construct equilibria, first suppose that the incentive constraint (4) does not bind, which implies, from (3), that $x=x^{*}$, where $x^{*}$ solves

$$
u^{\prime}\left(x^{*}\right)=1 \text {. }
$$

Then, from (3), we have $v=\frac{u\left(x^{*}\right)-x^{*}}{1-\beta}$, and checking the incentive constraint (4) with $\hat{v}=0$, this equilibrium exists if and only if

$$
\beta \geq \frac{x^{*}}{u\left(x^{*}\right)},
$$

i.e. buyers have to be sufficiently patient for this equilibrium to exist, in that they need to suffer sufficiently from the off-equilibrium punishment.

\subsubsection{Incentive Constraint Binds}

Next, suppose that the incentive constraint (4) binds. Then, $x=\beta v$, and from (3), $x$ solves

$$
x=\beta u(x) .
$$

Equation (6) has two solutions, one with $x=0$, and one with $x>0$. This first equilibrium always exists, and is inefficient, while the equilibrium with $x>0$ is efficient if it exists, and exists if and only if (checking that $x<x^{*}$ )

$$
\beta<\frac{x^{*}}{u\left(x^{*}\right)} .
$$

Thus, from (5) and (7), two equilibria exist, one with $x=0$ and one with $x>0$, and in the latter either the incentive constraint binds or it does not. Note that, in the equilibrium where $x>0$, efficient trade is supported in spite of the fact that the seller does not observe the buyer's history in a limited-information meeting during the $D M$. If a buyer defaults on any loan contract, whether the loan was received in a limited-information or full-information meeting, this will trigger global autarky, so that no loans are made on the off-equilibrium path.

\section{Government Debt}

A key element in our model will be the role played by government liquidity, and we want to ask what role this liquidity plays in the context of the credit frictions that exist in this environment. To emphasize our key points, we will assume that the government has no special powers in credit markets relative to private sector 
agents. The government cannot force people to work (limited commitment), and thus is no better at collecting on its debts - in the government's case the tax liabilities of private-sector agents - than are private creditors.

The government taxes buyers lump-sum in the $C M$, and issues one-period government bonds in the $C M$, each of which is a claim to one unit of consumption in the $C M$ of the next period. In the $C M$, agents first meet in a centralized location, where debts from the previous $D M$ are settled, taxes are paid to the government, and the government provides the payoffs on the government bonds issued in the previous period. Then, in the latter part of the $C M$, government bonds are sold on a Walrasian market in which exchange is anonymous.

Suppose that the government issues $B$ units of government bonds each period in the $C M$. Each bond sells, in the stationary equilibrium we consider, at the price $q$. Further, each buyer incurs a tax $\tau$ during the $C M$ to pay the net interest on the government's debt. Then, the continuation value $v$ is determined by

$$
v=\max _{l, b, b^{\prime}}\left\{-q b+u\left(l+\beta b-\beta b^{\prime}\right)-l+\beta b^{\prime}-\beta \tau+\beta v\right\}
$$

subject to

$$
\begin{gathered}
l+\beta \tau-\beta b^{\prime} \leq \beta(v-\hat{v}), \\
b^{\prime} \leq b
\end{gathered}
$$

where $l$ is the quantity borrowed by the buyer during the $D M, b$ denotes the quantity of bonds acquired by the buyer in the $C M$, and $b^{\prime}$ is the quantity of bonds that are not sold by the buyer in the subsequent $D M$, but are held to be redeemed in the next $C M$. Note that, in the incentive constraint (9), the left-hand side represents how much the buyer has to work to pay off his or her debts, where these debts include tax liabilities.

The key issue to address in the setup of problem (8) subject to (9) and (10), is the specification of the off-equilibrium punishment the buyer faces if he or she defaults. With global punishments, this is quite straightforward. If the government observes a default - either on tax liabilities or private debt - it will issue no debt in the current $C M$, and in every $C M$ in the future. A default by any individual then can trigger global autarky, which we know, from our analysis in the previous section, is an equilibrium when only private credit is available. Thus, $\hat{v}=0$.

In equilibrium, the demand for government debt is equal to the supply,

$$
b=B,
$$

and the government budget constraint holds, or

$$
\tau=B(1-q) .
$$

\subsubsection{Incentive Constraint Does Not Bind}

First, if the constraint (9) does not bind, then in equilibrium $l+\beta b-\beta b^{\prime}=x^{*}$, and $q=\beta$, so from (8), (11), and (12), we have

$$
v=\frac{u\left(x^{*}\right)-x^{*}-\beta B(1-\beta)}{1-\beta},
$$


and the incentive constraint (9) in equilibrium then reduces to (5), which is the same condition we obtained without government debt, and the equilibrium allocation is identical, so $B$ is irrelevant if (5) holds.

\subsubsection{Incentive Constraint Binds}

Next, consider the case where the incentive constraint (9) binds. Then, from (8)-(12), the quantity of consumption in the $D M, x$, solves (6), and

$$
q=\beta u^{\prime}(x)
$$

If the incentive constraint (9) binds, then from (8)-(12) and (14), we can write (8) as

$$
x=\beta u(x),
$$

and so an equilibrium with $x>0$ and a binding incentive constraint exists if and only if (7) holds. There also always exists an equilibrium with $x=0$. Thus, in this case $B$ is irrelevant, just as when the incentive constraint does not bind.

Therefore, in these equilibria with global punishments, the issue of government debt accomplishes nothing. With global punishments, the economy is Ricardian. In spite of the limited commitment friction, government debt is irrelevant as the government is no better at collecting on its debts than are private sector lenders. If the incentive constraint binds in the absence of government debt, then issuing government debt does not relax the incentive constraint, as taxation is required to support tradeable government debt, and buyers can default on their tax liabilities to the same extent they can default on their private debts.

It is important to note the differences here from some standard results in the economics literature. In the models considered by Woodford (1990), and Holmstrom and Tirole (1998), for example, there are credit market frictions that are closely related to what we consider here. In particular, Woodford con-

siders an environment with incomplete markets and an exogenous borrowing constraint, and Holmstrom and Tirole considered a limited commitment environment that restricts unsecured credit. However, in the work of Woodford (1990) and Holmstrom and Tirole (1998), the government has special powers relative to the private sector. Government liquidity improves matters because the government is able to enforce payment of taxes while the private sector is limited in its ability to collect on debts.

In our model, with symmetric debt collection abilities, Ricardian equivalence holds under global punishments. It should be clear why this happens in this environment, as the government is clearly doing nothing that a private sector agent could not do. It issues promises to pay, and the fact that these promises are issued in the $C M$ rather than the $D M$ does not make any difference. Those promises are kept as the government is able to collect taxes to pay off the government debt because of a threat of global autarky faced by defaulting taxpayers the same implicit threat faced by economic agents in the private credit economy. 


\section{Symmetric Equilibria with Individual Punish- ment}

Studying equilibria with global punishments, as in the previous section, serves as a useful baseline, but global punishments are obviously unrealistic. In this section, we construct equilibria with individual punishments, under which a default triggers retribution directed only against the individual defaulter, off equilibrium. As with global punishment equilibria, for now we confine attention to symmetric equilibria.

\subsection{Private Credit and No Government Debt}

Just as in the previous section, $v$ is determined by (3) subject to (4). But, with individual punishments, $\hat{v}$ will be different from the case with global punishments. If a buyer chooses to default, then off-equilibrium he or she will not receive a loan on meeting a seller in a full-information meeting in the $D M$. Off-equilibrium, sellers believe that a buyer who has defaulted will not receive a loan from any seller in a limited information meeting in the $D M$. Thus, a buyer who has defaulted has nothing to lose from defaulting in future periods, and thus continues to do so. Therefore, if a seller knows that a buyer has defaulted, then he or she strictly prefers not to lend.

If a buyer who has defaulted were in a limited-information meeting in the $D M$ during any period after default occurs, the seller does not know that this individual buyer defaulted. Thus, in limited information meetings the defaulting buyer will receive whatever loan $l$ other buyers receive in equilibrium. In limited information meetings, buyers and sellers have no incentive to change their behavior following the default of one individual, as that individual buyer will be encountered with probability zero. Thus, the continuation utility if default occurs is

$$
\hat{v}=\frac{\rho u(l)}{1-\beta} .
$$

\subsubsection{Incentive Constraint Does not Bind}

If there is efficient exchange in all $D M$ meetings, with $x=x^{*}$, then from (3) and (16) we obtain

$$
v-\hat{v}=\frac{(1-\rho) u\left(x^{*}\right)-x^{*}}{1-\beta},
$$

and checking the incentive constraint (4), this equilibrium exists if and only if

$$
\beta \geq \frac{x^{*}}{(1-\rho) u\left(x^{*}\right)} .
$$

\subsubsection{Incentive Constraint Binds}

Now, suppose that the incentive constraint (4) binds. Then from (3), (4), and (16), we can solve for the quantity of goods $x$ consumed by the buyer in the 
$D M$, i.e. $x$ solves

$$
x=\beta(1-\rho) u(x),
$$

and we require that the solution satisfy $x<x^{*}$, for the incentive constraint to bind. There always exists an equilibrium with $x=0$, and an equilibrium with $x>0$ exists if and only if

$$
\beta<\frac{x^{*}}{(1-\rho) u\left(x^{*}\right)} .
$$

\subsubsection{Individual Punishments vs. Global Punishments}

Not surprisingly, with weaker punishments relative to the global punishment case, the quantity of exchange and welfare are in general reduced. Let the welfare measure be the sum across agents of period utilities, so that welfare is denoted by

$$
W=u(x)-x .
$$

Then, welfare is increasing in $x$ for $x \leq x^{*}$. Let $x_{G}$ denote the quantity of goods exchanged in $D M$ meetings with global punishments, and $x_{I}$ the quantity with individual punishments. Then, from (5), (6), (7), (17), (18), and (19),

1. If $\beta \geq \frac{x^{*}}{(1-\rho) u\left(x^{*}\right)}$, then $x_{G}=x_{I}=x^{*}$ and welfare is the same whether there are global or individual punishments.

2. If $\frac{x^{*}}{u\left(x^{*}\right)} \leq \beta<\frac{x^{*}}{(1-\rho) u\left(x^{*}\right)}$, then $x_{G}=x^{*}>x_{I}$, and welfare is higher with global punishments.

3. If $\beta<\frac{x^{*}}{u\left(x^{*}\right)}$, then $x_{I}<x_{G}<x^{*}$, and welfare is higher with global punishments. ${ }^{2}$

Thus, with individual punishments - which are weaker than global punishments - the incentive constraint for buyers is tighter, in general. As a result, less exchange is supported in the $D M$, and welfare is lower.

\subsection{Equilibria with Government Debt}

To focus on whether government debt can improve matters, we will construct equilibria in which the government issues just enough debt to completely crowd out private credit. This will make our analysis more straightforward, and will also allow us to make fairly strong statements, as it turns out that these equilibria have nice welfare properties.

In the equilibria we construct, in which there is no private lending in the $D M$, and all government debt is exchanged by buyers in the $D M$, the buyer's

\footnotetext{
${ }^{2}$ When the incentive constraint binds with individual punishments, $x_{I}$ is determined by $x_{I}=\beta(1-\rho) u\left(x_{I}\right)$, whereas when the incentive constraint binds wtih global punishments $x_{G}$ is determined by $x_{G}=\beta u\left(x_{G}\right)$. Since $\rho<1$, therefore $x_{G}>x_{I}$.
} 
consumption in the $D M$ is given by $x=\beta b=\beta B$. Then, from (9) and (12), we can write the incentive constraint for a buyer as

$$
B(1-q) \leq v-\hat{v} .
$$

But what is $\hat{v}$, the continuation value if the buyer chooses (out of equilibrium) to default on his or her tax liabilities? Seemingly, private sector sellers have no incentive to punish an individual buyer for defaulting, off equilibrium, because there is always positive surplus for a seller to split with a buyer offering government debt in exchange for goods. Possibly the buyer can offer the seller a small fraction of the surplus in exchange, even if the seller knows the buyer has defaulted, and the buyer can then induce the seller to trade.

We need to make additional assumptions in this instance about the government's ability to punish tax cheats. As well, we will be consistent, in making the same assumptions about private and public sector punishment abilities. So, assume that there is a technology which permits an agent to post government debt as collateral, which means a creditor has the right to seize the collateral in the event of default. Seizure can only occur at the beginning of the $C M$. Then note that, in this environment, the outright exchange of government debt for goods in the $D M$ is equivalent to an arrangement where government debt is posted as collateral in a credit arrangement in the $D M$, with the threat that the collateral is seized if default occurs in the following $C M$.

Just as private agents have the ability to seize collateral at the beginning of the $C M$, the government has the ability to confiscate government debt in the same circumstances. If a buyer defaults then, off equilibrium, sellers in full information meetings in the $D M$ strictly prefer not to trade with a buyer who has defaulted. Why? If the buyer were to offer the seller government debt in exchange for goods in the $D M$, then the government would confiscate the government bonds from the seller when he or she arrived in the $C M$. If the defaulting buyer were to offer the seller a collateralized credit contract in the $D M$, then the government would confiscate the collateral in the next $C M$, and the buyer would default on the loan. Thus, in either case, the seller anticipates getting nothing in return for the goods he or she produces, and so strictly prefers not to trade. Similarly, off equilibrium a defaulting buyer and a seller might consider engaging in an unsecured credit contract in a full-information meeting in the $D M$. But in that case, the seller believes that no one will offer the buyer credit in the future, off equilibrium, so the seller understands that the buyer will default. Thus, a seller strictly prefers not to make a loan to a buyer, off equilibrium, if he or she knows the buyer has defaulted on his or her tax liabilities.

These assumptions about the seizure of assets and collateral seem quite natural and reasonable in light of what is feasible in reality. Secured private credit arrangements are ubiquitous, and government debt is typically considered a highly liquid asset - it is good collateral. Further, the government typically collects from tax defaulters through the seizure of assets, ${ }^{3}$ and is willing to

\footnotetext{
${ }^{3}$ See http://www.justice.gov/opa/pr/2013/August/13-tax-975.html for an example of
} 
punish third parties, for example under laws that hinder money-laundering. Moreover, under the US Bankruptcy Code any payment made by a bankrupt debtor in the 90 days prior to the bankruptcy filing, must be paid back to the bankruptcy court. ${ }^{4}$

In instances where a buyer who has defaulted is matched in a limited information meeting in the $D M$, the seller will trade with the buyer if and only if the buyer behaves in the same way as buyers who have not defaulted. If a seller were to trade with a buyer who had defaulted and who behaved differently, this would be detected by the government, with the same punishment as applied for full information meetings. Thus, it is optimal for a seller not to trade with an agent who can be identified as having defaulted. Therefore, in order to engage in any trades in the $D M$, a buyer who has defaulted must arrive in the $D M$ with $B$ government bonds. Therefore,

$$
\hat{v}=\max \left[0, \frac{-q B+\rho u(\beta B)+(1-\rho) \beta B}{1-\beta}\right],
$$

so a defaulting buyer chooses autarky, or to pool with non-defaulting buyers. For non-defaulting buyers, the presence of a single defaulter is irrelevant, off equilibrium.

In equilibrium, from (8),(11), and (12), the continuation value for a buyer is

$$
v=-q B+u(\beta B)-\beta B(1-q)+\beta v,
$$

and optimization by buyers implies that the bond price $q$ is determined by

$$
q=\beta u^{\prime}(\beta B) .
$$

The government's problem is:

$$
\max _{B}[u(\beta B)-\beta B]
$$

subject to (21), (23), (22), and (24), i.e. the government chooses the quantity of government bonds $B$ to maximize welfare - the surplus from trade in the $D M$ - which is in general determined in equilibrium from the solution $\hat{v}, v$, and $q$ to (23), (22), and (24), satisfying the incentive constraint (21).

\subsubsection{Incentive Constraint Does Not Bind}

If the choice of $B$ were unconstrained for the government, from (25) it would choose $x=\beta B=x^{*}$. Then, from (24), $q=\beta$, and from (23) and (22) we get

$$
v=\frac{-x^{*}+u\left(x^{*}\right)-x^{*}(1-\beta)}{1-\beta},
$$

agreements aiming at the freeze of bank accounts linked to tax evasion and prosection of banks failing to cooperate with the prosecution of tax evaders. See Chapter V, Articles 51-59

of the United Nation Convention against Corruption for an example of recovery of asset linked to illicit cross-border transfers.

${ }^{4}$ Unless the creditor proves that they are preferential transfers. See the U.S. Bankruptcy Code, Section 547. 


$$
\hat{v}=\frac{\rho\left[u\left(x^{*}\right)-x^{*}\right]}{1-\beta} .
$$

Checking the incentive constraint (21), this is the solution to the government's problem if and only if

$$
\beta \geq \frac{x^{*}}{(1-\rho) u\left(x^{*}\right)+\rho x^{*}}
$$

Note that, if (26) holds, and the government sets $B=\frac{x^{*}}{\beta}$, then efficient exchange in the $D M$ guarantees that no buyer in the $D M$ would want to make an offer to a seller involving private credit. Each buyer acquires $\frac{x^{*}}{\beta}$ units of government debt in the $C M$ at a price $q=\beta$, exchanges all of this debt for a surplusmaximizing quantity of goods in the $D M$, and then pays his or her taxes in the subsequent $C M$.

\subsubsection{Incentive Constraint Binds and $\hat{v}>0$}

If the solution to the government's problem is not $B=\frac{x^{*}}{\beta}$, then the incentive constraint (21) must bind. If the incentive constraint binds, we need to consider two possibilities. First, it may be the case that $\hat{v}>0$, so that a defaulting buyer prefers to mimic the equilibrium behavior of other buyers. Second, we could have $\hat{v}=0$, in which case a defaulting buyer prefers autarky. In this subsection, we consider the first case.

From (9) we have $q=\beta u^{\prime}(x)$ where $x$ is the quantity of goods exchanged in $D M$ meetings. Then, (21)-(23) imply that $x$ solves

$$
x\left[1-\beta u^{\prime}(x)\right]=\beta(1-\rho)[u(x)-x] .
$$

Proposition 1 For $x \in(0, \infty)$, equation (27) has a unique solution $x_{E}$.

Proof. Rewrite equation (27) as

$$
1-\beta u^{\prime}(x)=\beta(1-\rho)\left[\frac{u(x)}{x}-1\right] .
$$

The right-hand side of (28) is monotonically decreasing in $x$, since $u(\cdot)$ is strictly concave. The right-hand side of (28) tends to $\infty$ as $x \rightarrow 0$, and to 0 as $x \rightarrow \infty$. The left-hand side of (28) is monotonically increasing in $x$. The left-hand side of (28) tends to $-\infty$ as $x \rightarrow 0$ and to 1 as $x \rightarrow \infty$. Therefore, by the intermediate value theorem, and given monotonicity, there exists a unique $x_{E} \in(0, \infty)$ that solves (28) and (27).

An equilibrium of this type must involve a solution $x_{E}$ to (27), and we have shown that a unique solution always exists. However, for this to be an equilibrium of the type we are looking for, $x_{E}$ must satisfy two other properties. First, the incentive constraint binds if and only if $x_{E}<x^{*}$. Second, it must be the case that $\hat{v}>0$ in equilibrium, or $\phi\left(x_{E}\right)>0$, where

$$
\phi(x) \equiv-x u^{\prime}(x)+\rho u(x)+(1-\rho) x .
$$


and let $\tilde{x}$ denote the solution to

$$
\phi(\tilde{x})=0 .
$$

Proposition 2 Assume that $-\frac{x u^{\prime \prime}(x)}{u^{\prime}(x)}$ is constant. If $-\frac{x u^{\prime \prime}(x)}{u^{\prime}(x)} \geq 1-\rho$, then

$$
\beta<\frac{x^{*}}{(1-\rho) u\left(x^{*}\right)+\rho x^{*}}
$$

is necessary and sufficient for existence of an asymmetric equilibrium with individual punishments and a binding incentive constraint with $\hat{v}>0$. If $-\frac{x u^{\prime \prime}(x)}{u^{\prime}(x)}<$ $1-\rho$, then (30) and

$$
\beta>\frac{\tilde{x}}{(1-\rho)[u(\tilde{x})-\tilde{x}]+\tilde{x} u^{\prime}(\tilde{x})}
$$

are necessary and sufficient for existence, where $\tilde{x}$ solves $\phi(\tilde{x})=0$.

Proof. First determine necessary and sufficient conditions for a binding incentive constraint, i.e. $x_{E}<x^{*}$. If we rewrite (27) as (28), then the right-hand side of (28) is monotonically decreasing and the left-hand side of (28) is monotonically increasing. The previous proposition shows that the solution $x_{E}$ is unique, so it follows that $x_{E}<x^{*}$ if and only if (30) holds. Second, we want to find necessary and sufficient conditions for $\phi\left(x_{E}\right)>0$. Differentiating (29), we obtain

$$
\phi^{\prime}(x)=u^{\prime}(x)[-1+\rho+\eta]+1-\rho
$$

Therefore, if $\eta \geq 1-\rho$, then $\phi^{\prime}(x)>0$ for $0 \leq x \leq x^{*}$, and since $\phi(0)=0$ therefore $\phi(x)>0$ for $x \in\left[0, x^{*}\right.$. Thus, if $\eta \geq 1-\rho$ then (30) is necessary and sufficient for existence of the equilibrium. Alternatively, suppose $\eta<1-\rho$, then $\phi^{\prime}(0)=-\infty, \phi^{\prime \prime}(x)>0$ for $x \in\left[0, x^{*}\right], \phi(0)=0, \phi\left(x^{*}\right)=\rho\left[u\left(x^{*}\right)-x^{*}\right]>0$, so there exists a unique $\tilde{x} \in\left(0, x^{*}\right)$ which solves $\phi(\tilde{x})=0$. Further, $\phi(x)>0$ for $x \in\left(\tilde{x}, x^{*}\right]$, and $\phi(x) \leq 0$ for $x \in(0, \tilde{x}]$. It is then necessary and sufficient for $\phi\left(x_{E}\right)>0$ that $x_{E} \in\left(\tilde{x}, x^{*}\right)$. Then, once more using $(28), x_{E} \in\left(\tilde{x}, x^{*}\right)$ if and only if (30) and (31) hold.

\subsubsection{Incentive Constraint Binds and $\hat{v}=0$}

Next, we consider the case where the incentive constraint binds in the government's problem, and a buyer who defaults (off equilibrium) chooses autarky. In this case, from (21)-(24), the quantity of goods traded in $D M$ meetings, $x$, solves (15).

Proposition 3 Assume that $-\frac{x u^{\prime \prime}(x)}{u^{\prime}(x)}$ is constant. A necessary condition for existence of a symmetric equilibrium with individual punishments and a binding incentive constraint with $\hat{v}=0$ is (7). If $-\frac{x u^{\prime \prime}(x)}{u^{\prime}(x)} \leq 1-\rho$, then this equilibrium does not exist. If $-\frac{x u^{\prime \prime}(x)}{u^{\prime}(x)}>1-\rho$, then (7) and

$$
\beta \leq \frac{\tilde{x}}{u(\tilde{x})}
$$


are necessary and sufficient conditions for existence.

Proof. Checking that $x<x^{*}$, from (15) a necessary condition for the equilibrium to exist is (7). As well, $\hat{v}=0$ requires that a defaulting buyer not wish to mimic equilibrium behavior, which requires $\phi(x) \leq 0$. Therefore, this equilibrium does not exist if $-\frac{x u^{\prime \prime}(x)}{u^{\prime}(x)} \geq 1-\rho$, as this implies $\phi(x)>0$ for $x \in\left(0, x^{*}\right)$. If $-\frac{x u^{\prime \prime}(x)}{u^{\prime}(x)}<1-\rho$, then $\phi(x) \leq 0$ for $x \in[0, \tilde{x}]$, and so from (15), a necessary and sufficient condition for existence in this case is (33).

\subsubsection{Effects of Government Debt with Individual Punishments}

Government debt clearly matters in equilibria with individual punishments, as the equilibrium allocation with government debt is in general different from the one without government debt. Thus, Ricardian equivalence does not hold in general, in spite of the fact that the government has no special powers relative to private sector agents. We want to compare welfare with and without government debt, using our measure of welfare (20), which implies that welfare is increasing in the quantity of goods $x$ exchanged in each meeting in the $D M$, for $x \leq x^{*}$, which will always hold in equilibrium. The following proposition demonstrates that government debt at worst has no effect on welfare and at best increases it by increasing the volume of exchange in the $D M$. Let $x_{N}$ denote the quantity of goods exchanged in each meeting in the $D M$ in the absence of government debt, and $x_{D}$ the quantity exchanged when there is government debt.

Proposition 4 (i) If $\beta \geq \frac{x^{*}}{(1-\rho) u\left(x^{*}\right)}$, then $x_{D}=x_{N}=x^{*}$, and welfare is the same in the equilibrium without government debt and the one with government debt. (ii) If $\frac{x^{*}}{(1-\rho) u\left(x^{*}\right)+\rho x^{*}} \leq \beta<\frac{x^{*}}{(1-\rho) u\left(x^{*}\right)}$, then $x^{*}=x_{D}>x_{N}$, and welfare is greater with government debt than without. (iii) If $-\frac{x u^{\prime \prime}(x)}{u^{\prime}(x)}$ is constant, if $-\frac{x u^{\prime \prime}(x)}{u^{\prime}(x)} \geq 1-\rho$ or if $-\frac{x u^{\prime \prime}(x)}{u^{\prime}(x)}<1-\rho$ and $\beta>\frac{\tilde{x}}{(1-\rho)[u(\tilde{x})-\tilde{x}]+\tilde{x} u^{\prime}(\tilde{x})}$, and $\beta<$ $\frac{x^{*}}{(1-\rho) u\left(x^{*}\right)+\rho x^{*}}$, then $x_{N}<x_{D}<x^{*}$. (iv) If $-\frac{x u^{\prime \prime}(x)}{u^{\prime}(x)}$ is constant, if $-\frac{x u^{\prime \prime}(x)}{u^{\prime}(x)}>$ $1-\rho$ and $\beta \leq \frac{\tilde{x}}{u(\tilde{x})}$, then $x_{N}<x_{D}<x^{*}$.

Proof. (i) From (17) and (26), equilibria with a nonbinding incentive constraint exist if $\beta \geq \frac{x^{*}}{(1-\rho) u\left(x^{*}\right)}$, both with and without government debt. (ii) From (26), the incentive constraint does not bind with government debt if $\frac{x^{*}}{(1-\rho) u\left(x^{*}\right)+\rho x^{*}} \leq$ $\beta<\frac{x^{*}}{(1-\rho) u\left(x^{*}\right)}$, so $x_{D}=x^{*}$. However, since (19) holds, the incentive constraint binds without government debt, so $x_{N}<x^{*}$. (iii) From (19), (30), and (31), the incentive constraint binds in both equilibria, so $x_{N}<x^{*}$ and $x_{D}<x^{*}$. Further, we can write equation (18) as

$$
x[1-\beta(1-\rho)]=\beta(1-\rho)[u(x)-x] .
$$

Then, since the right-hand sides of equations (34) and (27) are identical, and $u^{\prime}(x)>1-\rho$ for $x<x^{*}$, therefore $x_{D}>x_{N}$. (iv) From (19) and (33), the 
incentive constraint binds in both equilibria, so $x_{N}<x^{*}$ and $x_{D}<x^{*}$. In the equilibrium with no government debt, $x$ is determined by (18), and in the equilibrium with government debt, $x$ is determined by (15). It is immediate from (18) and (15) that $x_{N}<x_{D}$.

Note that, since

$$
-\tilde{x} u^{\prime}(\tilde{x})+\rho u(\tilde{x})+(1-\rho) \tilde{x}=0
$$

determines $\tilde{x}$, therefore

$$
\frac{\tilde{x}}{u(\tilde{x})}=\frac{\tilde{x}}{(1-\rho)[u(\tilde{x})-\tilde{x}]+\tilde{x} u^{\prime}(\tilde{x})},
$$

so the right-hand sides of inequalities (31) and (33) are equal. As a result, the above proposition exhausts the parameter space. With government debt, the equilibrium is unique among the class of equilibria we are examining in this section, and an equilibrium always exists. The same is the case without government debt.

Figure 2 shows how the parameter space is subdivided, with the parameter $\rho$ on the horizontal axis, and $\beta$ on the vertical axis. In region 1 , part (i) of the above proposition applies. In this case, the incentive constraint does not bind with or without government debt, and there is efficient exchange in either case, or $x_{N}=x_{D}=x^{*}$. In region 2, part (ii) of the above proposition applies, in which case the incentive constraint binds without government debt, but does not bind with government debt, or $x_{N}<x_{D}=x^{*}$. In region 2 , the introduction of government debt is welfare-improving, as it increases exchange in the $D M$. In region 3, part (iii) of the above proposition applies, with incentive constraints binding in equilibrium with or without government debt. With government debt, defaulting buyers choose to mimic equilibrium behavior, or $\hat{v}>0$. In region 3 , exchange is greater in the $D M$ with government debt, and welfare is higher. Finally, in region 4 of the parameter space, in Figure 3, part (iv) of the above proposition applies. In this case, the incentive constraint binds with or without government debt, but there is more exchange in the $D M$, and higher welfare, with government debt. In the equilibrium with government debt in region 4 , defaulting buyers choose autarky, or $\hat{v}=0$.

[Figure 2 here.]

We can conclude from the above four propositions that introducing government debt in symmetric equilibria with individual punishments is welfare improving as, in general, it increases the quantity of exchange in decentralized meetings. The introduction of government debt acts to relax incentive constraints, as it tends to make default - in this case on government debt rather than private debt - less desirable. At best, the introduction of government debt can make it so costly to mimic equilibrium behavior for a defaulting buyer, that a buyer will choose autarky if default occurs, off-equilibrium. In the absence of government debt, a buyer who defaults can get something for nothing. By 
simply posing as a buyer who has not defaulted, a defaulting buyer can receive a loan with probability $\rho$. However, when government debt is traded, a defaulting buyer has to work to acquire the government debt in order to pose as a buyer who has not defaulted.

Some readers may be puzzled as to why the welfare-improving role of government debt is not generated from a liquidity premium on government debt that implies positive transfers from the government, which of course all buyers are willing to accept. For example, if the incentive constraint is tight, then $x$ is small in equilibrium, so from (14) $q$ is high, and if $q>1$, then from (12) the tax is negative. Then, there would be no potential default problem. But from our analysis above, it is straightforward to show that $q<1$ in the equilibria with government debt we consider. To see why $q<1$ given the optimal provision of government debt, if $q \geq 1$ at the optimum, then $x<x^{*}$. But this implies that the government could increase the quantity of government debt, increase welfare, and the incentive constraint of buyers would still hold. Thus, $q \geq 1$ cannot be optimal.

As discussed above, we can interpret exchange as occurring in the government debt economy by way of outright exchange of government debt for goods in the $D M$, or as a credit arrangement with government debt used as collateral. With the collateral contract, the buyer can sell the government debt in the next $C M$ in order to repay the debt. Effectively, the government supplies a safe asset, supported by taxation, that is used to support credit market activity. With a ready supply of government debt, the collateralized credit arrangements arise endogenously, and they increase welfare by promoting more exchange. This role for government debt as collateral in the credit market is consistent with empirical observations (see Garbade 2006), in that activity in the repurchase agreement market appears to have grown partly in response to growth in the quantity of government debt outstanding in the United States.

Intuition might tell us that the provision of government debt might be bad for incentives in this context, since it potentially allows for anonymous exchange. The possibility of defecting from the credit system might look more desirable if there is another mode of exchange available. Indeed, this intuition captures the forces at work in Aiyagari and Williamson (2000). In Aiyagari-Williamson (2000), exchange of government liabilities (fiat money, in that case) provides an alternative to participation in a credit system, and the better this system of government-liability exchange works, the worse that is for incentives in the credit system. In the Aiyagari-Williamson (2000) model, government liabilities are effectively a substitute for credit, while in this model (at least in the symmetric equilibria we have studied thus far) government liabilities are complementary to credit, as government debt essentially serves as collateral. This is important, as the non-anonymous nature of government debt is what contributes to its role in improving welfare. In this sense, it is inappropriate to think of the role of the government liquidity here as the same as what we would find in typical monetary models.

Could an arrangement with private debt yield the same type of improvement in welfare as we get with government debt? First, note that it is sufficient to 
consider one-period private debt as an alternative to government debt, as any long-term debt arrangement can be broken down into a series of one-period debt problems in this model. Our interest is in the potential for debt issued by one party, and acquired by another party and traded, to serve the same role as government debt. So, suppose that a buyer in the $C M$ sells bonds that are claims to consumption goods in the next $C M$. These private bonds can then be exchanged by buyers in the intervening $D M$ for consumption goods. But when a seller meets a buyer, the seller does not care whether the IOUs being offered are promises to pay of the buyer on the other side of the transaction, or promises to pay of a third private party. The seller is concerned only with whether or not the issuer of the IOU will default or not, and that issuer has exactly the same incentives in either case. Therefore circulating private debt cannot solve the problem.

\section{Asymmetric Equilibria with Individual Pun- ishment and Equilibrium Default}

We will now consider equilibria where agents behave asymmetrically, with some buyers defaulting in equilibrium. These are equilibria where a fraction $\alpha$ of buyers (the good buyers) never defaults, but a fraction $1-\alpha$ (bad buyers) will default on their debts if anyone chooses to lend to them. It will in general be possible to support equilibria with differing values for $\alpha$. Indeed, a special case involves equilibria with $\alpha=1$, which we have already considered. Thus, note that $\alpha$ is endogenous but, as we hope to make clear, it is indeterminate. In an asymmetric equilibrium, good buyers never default because they would be punished for default by being treated in the same way as bad buyers, thus losing access to exchange in the $D M$ under full information. Bad buyers always default as they have nothing to lose - sellers who know their type will not lend to them.

In typical limited commitment models of credit, such as Kehoe and Levine (1993), Kocherlakota (1996), or Sanches and Williamson (2010), there is no default in equilibrium, just as in the symmetric equilibria in our model. While the threat of default can be important in constraining credit contracts in those models, the fact that default does not occur in equilibrium limits the ability of such models to explain observations. In models of bankruptcy with incomplete markets, such as Athreya (2002) and Corbae et al. (2007), it is typical to assume that contracts take the form of non-contingent debt, and there is then equilibrium default. Of course, much is imposed in such models, including the absence of contingent claims markets, and restrictions on contracts. In our model, the contracts are optimal given the economic environment, but default can occur in equilibrium. 


\subsection{Private Credit and No Government Debt}

In the equilibria we construct, bad buyers will always default on a loan received from a seller in the $D M$. Therefore, if a bad buyer meets a seller in a fullinformation meeting, the buyer will not receive a loan. Similarly, since a good buyer does not default in equilibrium, the good buyer will receive a loan in a full-information meeting, as the seller knows the buyer's type. Since the buyer makes a take-it-or-leave it offer in a full-information meeting, the offer of a good buyer will take the form of a loan quantity $x_{F}$, which is the quantity of consumption goods produced by the seller for the buyer in the $D M$, coupled with a repayment $\frac{x_{F}}{\beta}$ by the buyer in the next $C M$.

The situation is potentially more complicated if a good buyer or bad buyer meets a seller in a limited-information meeting. Given our assumption that the buyer makes a take-it-or-leave-it offer in the $D M$, a limited information meeting involves signalling under private information. Our candidate equilibrium is a pooling equilibrium in $D M$ limited information meetings, in which all buyers (good and bad) make an offer $x_{L}$ to the seller in a limited-information meeting in the $D M$, and promise a repayment $\frac{x_{L}}{\alpha \beta}$ in the next $C M$. To completely specify the signalling game, we need to add beliefs for the seller, including those for off-equilibrium offers by buyers. Let the beliefs of the seller be that, for any offer received, the probability that the offer is from a good buyer is $\alpha$. Thus, in equilibrium, the seller is indifferent to accepting an offer from a buyer given the seller's beliefs, which are correct in equilibrium. The offer made by a good buyer is a best response to the seller, given the seller's beliefs, and a bad buyer clearly optimizes by making the same offer as a good buyer, as posited.

There are equilibrium refinements that could eliminate this equilibrium from consideration. A good discussion of this is in the appendix of Rocheteau (2008), for a related model. For example, if we use the intuitive criterion (Cho and Kreps 1987), then the good buyer could deviate from the equilibrium contract by offering to accept slightly less than $x_{L}$ in exchange for a payment $\frac{x_{L}}{\beta}$ to the seller in the next $C M$, which the seller and the good buyer both strictly prefer to the equilibrium contract. Further, the bad buyer strictly prefers the equilibrium contract to the deviation, so the proposed equilibrium is ruled out by the intuitive criterion. But, using the notion of undefeated equilibrium (Mailath et al. 1993), which is arguably deeper than the intuitive criterion, we ask more of a deviation. In this model, any equilibrium must be a pooling equilibrium for limited information exchange, as the seller would never want to trade with a buyer who he or she identifies as bad. Thus, under undefeated equilibrium, deviations involve cases where, in this model, the seller believes that an offequilibrium offer comes from a good buyer with probability $\alpha$. By construction of the pooling equilibrium we consider (which gives the seller zero expected surplus), good and bad buyers must be worse off for any deviation. Thus, the equilibrium we focus on is undefeated.

Therefore, in the absence of government debt, the continuation value $v$ for 
a good buyer is given by

$$
v=\max _{x_{L}, x_{F}}\left\{\rho u\left(x_{L}\right)+(1-\rho) u\left(x_{F}\right)-\rho \frac{x_{L}}{\alpha}-(1-\rho) x_{F}+\beta v\right\}
$$

subject to

$$
\begin{aligned}
& \frac{x_{L}}{\alpha} \leq \beta(v-\hat{v}), \\
& x_{F} \leq \beta(v-\hat{v})
\end{aligned}
$$

Note that, in the pooling equilibrium, limited-information loans carry a default premium. Constraints (36) and (37) are the incentive constraints that must hold for a good buyer following a limited-information meeting and a full-information meeting, respectively. Here, $\hat{v}$ is not only the off-equilibrium continuation utility the good buyer receives if he or she defaults, but the continuation utility of a bad buyer, who always defaults.

A bad buyer consumes the same quantity as a good buyer in a limited information meeting, and consumes zero in a full-information meeting in the $D M$, so

$$
\hat{v}=\frac{\rho u\left(x_{L}\right)}{1-\beta} .
$$

If neither incentive constraint, (36) or (37), binds, then $x_{L}=\hat{x}$ and $x_{F}=x^{*}$, where $\hat{x}$ solves

$$
u^{\prime}(\hat{x})=\frac{1}{\alpha} .
$$

Clearly $\hat{x}<x^{*}$ for $\alpha<1$, so a smaller quantity of goods is exchanged in limited information meetings, even if incentive constraints do not bind. Further, since $-\frac{x u^{\prime \prime}(x)}{u^{\prime}(x)}<1, \frac{\hat{x}}{\alpha}<x^{*}$ for $\alpha<1$, which implies that, in equilibrium, incentive constraint (37) is always tighter than (36). Thus, the only cases we need to consider, in the absence of government debt, are equilibria where neither incentive constraint binds, where constraint (37) binds and (36) does not, and where both incentive constraints bind. We will consider each of these three cases in turn.

\subsubsection{Neither Incentive Constraint Binds}

If (36) and (37) do not bind, then from (35) - (38) we get

$$
v-\hat{v}=\frac{(1-\rho) u\left(x^{*}\right)-\rho \frac{\hat{x}}{\alpha}-(1-\rho) x^{*}}{1-\beta} .
$$

To check incentive constraints, it is sufficient to check (37), as this is always the tighter constraint. This tells us that this equilibrium exists if and only if

$$
\beta \geq \frac{x^{*}}{(1-\rho) u\left(x^{*}\right)+\rho\left(x^{*}-\frac{\hat{x}}{\alpha}\right)}
$$




\subsubsection{Limited Information Incentive Constraint Does Not Bind, Full- Information Incentive Constraint Does}

Next, we analyze the case where (36) does not bind, but (37) does. Then, from (35) - (38) we get

$$
\begin{gathered}
v=\rho u(\hat{x})+(1-\rho) u[\beta(v-\hat{v})]-\rho \frac{\hat{x}}{\alpha}+\beta \rho v+\beta(1-\rho) \hat{v}, \\
\hat{v}=\rho u(\hat{x})+\beta \hat{v}
\end{gathered}
$$

and then (41), (42), and (37) with equality gives

$$
\beta(1-\rho) u\left(x_{F}\right)-x_{F}+\rho \beta\left(x_{F}-\frac{\hat{x}}{\alpha}\right)=0,
$$

which solves for $x_{F}$. There are potentially two solutions to (43), one solution with $x_{F}<\frac{\hat{x}}{\alpha}$, and one with $x_{F}>\frac{\hat{x}}{\alpha}$. Only the latter can be an equilibrium as, if $x_{F}<\frac{\hat{x}}{\alpha}$, then incentive constraint (36) must bind, but we are attempting to construct an equilibrium in which this constraint does not bind. For an equilibrium, we first require that there be a solution to (43). A necessary and sufficient condition for that is

$$
\beta \geq \frac{\frac{\hat{x}}{\alpha}}{(1-\rho) u\left(\frac{\hat{x}}{\alpha}\right)} .
$$

As well, we require that the solution satisfy $x_{F}<x^{*}$, so that the full-information incentive constraint binds or, from (43),

$$
\beta<\frac{x^{*}}{(1-\rho) u\left(x^{*}\right)+\rho\left(x^{*}-\frac{\hat{x}}{\alpha}\right)} .
$$

Then, (44) and (45) are necessary and sufficient conditions for this equilibrium to exist.

\subsubsection{Both Incentive Constraints Bind}

If (36) and (37) bind, then $x_{L}=\alpha x_{F}$, and from (35) - (38), $x_{F}$ solves

$$
x_{F}=\beta(1-\rho) u\left(x_{F}\right) .
$$

To determine necessary and sufficient conditions for existence, it is sufficient to check that the solution to (46) implies that the incentive constraint (36) binds, since (37) is always the tighter constraint. Thus, we require that $x_{F}<\frac{\hat{x}}{\alpha}$, which from (46) gives

$$
\beta<\frac{\frac{\hat{x}}{\alpha}}{(1-\rho) u\left(\frac{\hat{x}}{\alpha}\right)} .
$$

Then, inequality (47) is necessary and sufficient for the existence of this equilibrium. 


\subsubsection{Asymmetric Equilibria vs. Symmetric Equilibria}

The presence of defaulting borrowers in equilibrium has two sets of effects. First, there are direct effects on good borrowers in limited-information credit arrangements. There is an adverse selection problem, with a fraction $1-\alpha$ of bad buyers who borrow from sellers in limited-information meetings and then default. Good buyers in these meetings will be able to borrow less than if there were full information. Consumption will then be lower in limited-information meetings. The indirect effects on good borrowers are incentive effects. Following a limited information meeting in the $D M$, a good borrower will have less debt to pay off, in spite of having to pay a default premium to the seller (this depends on curvature in the utility function; if the coefficient of relative risk aversion is greater than one, this effect goes the other way). Perhaps counterintuitively, the presence of defaulting borrowers can make default less likely for good borrowers, in the sense that incentive constraints are relaxed.

More explicitly, note first that

$$
\frac{x^{*}}{(1-\rho) u\left(x^{*}\right)+\rho\left(x^{*}-\frac{\hat{x}}{\alpha}\right)}<\frac{x^{*}}{(1-\rho) u\left(x^{*}\right)}
$$

and

$$
\frac{\frac{\hat{x}}{\alpha}}{(1-\rho) u\left(\frac{\hat{x}}{\alpha}\right)}<\frac{x^{*}}{(1-\rho) u\left(x^{*}\right)},
$$

for $0<\alpha<1$. Therefore, from (17), (19), (40) and (47), if $\alpha$ falls, so that there are fewer good buyers in the population, this acts to relax incentive constraints, expand the region of the parameter space in which incentive constraints do not bind, and shrink the region where incentive constraints bind. For this result, it is important that $-x \frac{u^{\prime \prime}(x)}{u^{\prime}(x)}<1$, which implies that $\frac{\hat{x}}{\alpha}$ is increasing in $\alpha .^{5}$

Therefore, if

$$
\beta \geq \frac{x^{*}}{(1-\rho) u\left(x^{*}\right)},
$$

then from (17), (40), and (48), incentive constraints do not bind in a symmetric equilibrium or in any asymmetric equilibrium with $0<\alpha<1$. But, since $\hat{x}<x^{*}$, consumption is smaller in limited information meetings in the $D M$ in asymmetric equilibria than in the symmetric equilibrium, and consumption is the same in full information meetings. Therefore, welfare is higher in the symmetric equilibrium in this case.

If

$$
\beta<\frac{\frac{\hat{x}}{\alpha}}{(1-\rho) u\left(\frac{\hat{x}}{\alpha}\right)},
$$

then given (49), the incentive constraint binds in the symmetric equilibrium, and both incentive constraints bind in an asymmetric equilibrium. But from

\footnotetext{
${ }^{5}$ The result goes the other way if $-x \frac{u^{\prime \prime}(x)}{u^{\prime}(x)}>1$.
} 
(46) and (18), consumption is the same in full information meetings in the symmetric and asymmetric equilibria, but is smaller in limited information meetings in the asymmetric equilibrium. Therefore, welfare is higher in the symmetric equilibrium.

In the case where

$$
\beta \in\left[\frac{\frac{\hat{x}}{\alpha}}{(1-\rho) u\left(\frac{\hat{x}}{\alpha}\right)}, \frac{x^{*}}{(1-\rho) u\left(x^{*}\right)}\right),
$$

it is difficult to make comparisons between symmetric and asymmetric equilibria.

Multiplicity of Asymmetric Equilibria One feature of asymmetric equilibria that we did not see with symmetric equilibria is that, for given $\alpha$, there can be multiple equilibria. From (40), (44), (45), and (47), if

$$
0<\rho<\frac{\frac{u\left(\frac{\hat{x}}{\alpha}\right)}{\frac{\hat{x}}{\alpha}}-\frac{u\left(x^{*}\right)}{x^{*}}}{\frac{u\left(\frac{\hat{x}}{\alpha}\right)}{\frac{\hat{x}}{\alpha}}-\frac{u\left(x^{*}\right)}{x^{*}}+1-\frac{\frac{\hat{x}}{\alpha}}{x^{*}}},
$$

then for high $\beta$, neither incentive constraint binds, for middle levels of $\beta$ the limited-information incentive constraint does not bind while the other incentive constraint does, and for low levels of $\beta$ both incentive constraints bind. However, if

$$
\frac{\frac{u\left(\frac{\hat{x}}{\alpha}\right)}{\frac{\hat{x}}{\alpha}}-\frac{u\left(x^{*}\right)}{x^{*}}}{\frac{u\left(\frac{\hat{x}}{\alpha}\right)}{\frac{\hat{x}}{\alpha}}-\frac{u\left(x^{*}\right)}{x^{*}}+1-\frac{\frac{\hat{x}}{\alpha}}{x^{*}}}<\rho \leq \frac{u\left(x^{*}\right)-x^{*}}{u\left(x^{*}\right)-x^{*}+\frac{\hat{x}}{\alpha}},
$$

then for middle levels of $\beta$ two equilibria exist - the equilibrium where neither incentive constraint binds and the one where both incentive constraints bind, as the following proposition summarizes.

Proposition 5 Suppose (50) holds and

$$
\beta \in\left[\frac{x^{*}}{(1-\rho) u\left(x^{*}\right)+\rho\left(x^{*}-\frac{\hat{x}}{\alpha}\right)}, \frac{\frac{\hat{x}}{\alpha}}{(1-\rho) u\left(\frac{\hat{x}}{\alpha}\right)}\right) .
$$

Then, for given $\alpha$, there exist two equilibria, one where neither incentive constraint binds, and one where both incentive constraints bind.

Proof. Consider the necessary and sufficient conditions for existence of equilibria with neither incentive constraint binding, (40), and both incentive constraints binding, (47). The set defined by (50) and (51) is the set satisfying (40) and (47). Then, any $(\rho, \beta)$ satisfying (50) and (51) is such that both (40) and (47) are satisfied, so both equilibria exist. 


\subsubsection{Discussion: Private Credit and No Government Debt}

In asymmetric equilibria, limited commitment of course plays a key role, but limited recordkeeping introduces an additional friction that gives novelty to the results. In these equilibria, asymmetric information in limited information meetings in the $D M$ is important, but not because would-be borrowers are intrinsically different, or because of hidden actions. Buyers who wish to borrow from sellers are different because they receive different treatment in the future, which affects their future payoffs and willingness to default. This is why there is nothing that good borrowers can do to distinguish themselves from bad ones. There is no action that a good borrower can take that a bad borrower would for some reason choose not to take, and which would thus reveal the good borrower's type.

The result is an equilibrium in which bad borrowers sometimes get loans, and then proceed to default on those loans. Good borrowers do not default, because they have too much to lose from being treated like bad borrowers in the future. Bad borrowers default because they have nothing to lose from doing so.

\subsection{Asymmetric Equilibria with Government Debt}

If we consider asymmetric equilibria in which government debt exists, it is not obvious why this should mitigate or eliminate the inefficiencies stemming from the limited commitment friction. Government debt provides a means for supporting exchange in the $D M$ that seemingly does not depend on self-enforcing private credit contracts. Buyers can acquire government debt and then sell it outright for goods in the $D M$, or can engage in collateralized borrowing in the $D M$, with government debt used as collateral (these two types of exchange are equivalent). But taxation is required to support government debt, so what if buyers can default on their tax liabilities? Perhaps we can support equilibria in which there are good and bad credit risks, in the sense that some economic agents never pay their taxes, but are still able to trade in the $D M$ ?

In this section, we take the same approach as for symmetric equilibria, in constructing equilibria in which the quantity of bonds issued by the government is just sufficient to drive out private credit. In this case however, we are constructing equilibria for given $\alpha$, and then characterizing such equilibria and determining under what conditions they exist. In these equilibria, there is a mass $\alpha$ of good buyers who trade government bonds for goods in limitedinformation and full-information meetings in the $D M$, and who always pay their taxes in the $C M$. There is also a mass of $1-\alpha$ of bad buyers, who are able to trade in limited-information meetings in the $D M$ if they mimic the behavior of good buyers, but cannot trade in full-information $D M$ meetings. These bad buyers always default on their tax liabilities.

We will follow the same approach as in symmetric equilibria with government bonds, in assuming that the government is able to confiscate government debt at the beginning of the $C M$. Again, the rationale is that a technology exists which allows private agents to post government debt as collateral in a private credit 
contract, and this collateral can be seized in the event of default. If we permit the government to have the same powers as private sector agents, this means that we allow the government the latitude to write laws specifying contingencies under which government debt can be seized, and allow it to follow through when those contingencies arise.

As in the symmetric case, we construct an equilibrium with government debt in which consumption in the $D M$ by good buyers is $x=\beta B$, where $B$ now denotes the quantity of debt the government issues per good buyer. Then, the continuation utility $\hat{v}$ for the bad buyer is given by (22). The incentive constraint for the good buyer depends on whether $\hat{v}=0$ (the bad buyer chooses autarky) or $\hat{v}>0$. In the former case, the behavior of the bad buyer is irrelevant for good buyers, while in the latter case the bad buyers default on their tax liabilities, so the good buyers will bear the tax burden associated with servicing government debt held by bad buyers. If $\hat{v}=0$, then the incentive constraint for good buyers is given by (21), and $v$ is determined by (23). However, if $\hat{v}>0$ then a good buyer's incentive constraint is

$$
\frac{B(1-q)}{\alpha} \leq v-\hat{v}
$$

and the continuation value for a good buyer is given by

$$
v=-q B+u(\beta B)-\frac{\beta B(1-q)}{\alpha}+\beta v .
$$

As well, whether or not bad buyers hold government debt in equilibrium, optimization by the good buyer implies that the bond price $q$ is determined by (24).

The equilibria we construct have a similar structure of off-equilibrium punishments to the symmetric case. Assume that, in full information meetings in the $D M$, a seller understands that, if he or she were to engage in exchange with a bad buyer - either in the form of an outright exchange of government debt for goods, or a lending arrangement with government debt as collateral then the government would either seize the government debt from the seller, or seize the buyer's collateral, at the beginning of the next $C M$. Then, the seller's off-equilibrium expected utility from accepting a contractual offer from a buyer who the seller knows is bad, is strictly dominated by refusal of the offer. ${ }^{6}$

We assume that the government seizes no assets in connection with limited information exchange, as the seller is uninformed about the buyer's type in those meetings, so there is no direct gain from dissuading the seller from trading in limited information meetings in the $D M$. To keep things simple, we do not

\footnotetext{
${ }^{6}$ It is important to notice that in order to support these equilibria, it is sufficient that collateral -government debt- be seized only when a bad buyer actually trades in full information meetings and defaults on those loans. If the bad buyer does not get to trade there is no need to seize his or her holdings of government debt to support equilibria with endogenous default. The bad buyer can redeem those bonds in the CM to consume CM goods. This is not an irrelevant detail because in order to support default in equilibrium, it is necessary that the punishment for default is not too severe.
} 
search for optimal government policies in this context. We only want to show that there is potential for the introduction of government debt to improve the equilibrium allocation.

\subsubsection{Incentive Constraint Does Not Bind}

If the good buyer's incentive constraint does not bind, then we construct an equilibrium where solving (25) gives $\beta B=x^{*}$, and from (24), $q=\beta$. Then, if a bad buyer mimics the behavior of a good buyer, by purchasing $B$ government bonds in the $C M$, exchanging all of these bonds for consumption in limited information meetings in the $D M$, and holding the bonds until the next $C M$ in the event that there is a full information meeting in the $D M$, the continuation value for the bad buyer is

$$
\hat{v}=\frac{\rho\left[u\left(x^{*}\right)-x^{*}\right]}{1-\beta}>0 .
$$

Therefore, bad buyers will mimic the behavior of good buyers in limited information meetings in the $D M$, as this is preferable to autarky. Then, from (53) and (54),

$$
v-\hat{v}=\frac{(1-\rho) u\left(x^{*}\right)-\frac{x^{*}(1-\beta)}{\alpha}-(1-\rho) x^{*}}{1-\beta} .
$$

To determine existence of this equilibrium, it is sufficient to check the incentive constraint (52), so from (52) and (55) we obtain

$$
\beta \geq \frac{x^{*}}{\alpha(1-\rho) u\left(x^{*}\right)+[1-\alpha(1-\rho)] x^{*}},
$$

Inequality (56) is then a sufficient condition for an equilibrium of this type to exist for given $\alpha$.

\subsubsection{Incentive Constraint Binds and $\hat{v}>0$}

Next, consider the case where the asymmetric equilibrium with government debt involves a binding incentive constraint, and $\hat{v}>0$, so that bad buyers strictly prefer to mimic good buyers in limited information meetings in the $D M$. If (52) binds, then the quantity of consumption in $D M$ meetings is $x=\beta B$, and the price of government bonds in the $C M$ is $q=\beta u^{\prime}(x)$. Then, from (52), and (53), $x$ solves

$$
x\left[1-\beta u^{\prime}(x)\right]=\alpha \beta(1-\rho)[u(x)-x] .
$$

A unique solution to (57) exists, and we require that the incentive constraint bind, or $x<x^{*}$. Thus, from (57), a necessary condition for an equilibrium of this type to exist is

$$
\beta<\frac{x^{*}}{\alpha(1-\rho) u\left(x^{*}\right)+[1-\alpha(1-\rho)] x^{*}} .
$$


Further, we require $\hat{v}>0$. As in our analysis in the symmetric equilibrium case, suppose that $-\frac{x u^{\prime \prime}(x)}{u^{\prime}(x)}$ is constant. Then, as we showed above, if $-\frac{x u^{\prime \prime}(x)}{u^{\prime}(x)} \geq$ $1-\rho$, then $\hat{v}>0$, and if $-\frac{x u^{\prime \prime}(x)}{u^{\prime}(x)}<1-\rho$ then $\hat{v}>0$ if and only if $x>\tilde{x}$ where $\tilde{x}$ solves

$$
-\tilde{x} u^{\prime}(\tilde{x})+\rho u(\tilde{x})+(1-\rho) \tilde{x}=0 .
$$

Then, since the left-hand side of (57) is increasing in $x$ and the right-hand side is decreasing in $x,(57)$ and (59) imply $x>\tilde{x}$ if and only if

$$
\beta>\frac{\tilde{x}}{\alpha(1-\rho)[u(\tilde{x})-\tilde{x}]+\tilde{x} u^{\prime}(\tilde{x})}
$$

\subsubsection{Incentive Constraint Binds and $\hat{v}=0$}

In this case, $x=\beta \frac{B}{\alpha}$, since bad buyers do not hold bonds, and $q=\beta u^{\prime}(x)$. Then, from (52), and (53), $x$ solves (6). A necessary condition for this equilibrium to exist is that $x<x^{*}$, which from (6) gives (7). As well, bad buyers must not prefer to mimic the behavior of good buyers in limited information meetings in the $D M$, i.e.

$$
-x u^{\prime}(x)+\rho u(x)+(1-\rho) x \leq 0 .
$$

But (61) holds if and only if $-\frac{x u^{\prime \prime}(x)}{u^{\prime}(x)}<1-\rho$ and $x \leq \tilde{x}$, where $\tilde{x}$ is defined by (59). But from (6) and (59), $x \leq \tilde{x}$ is equivalent to

$$
\beta \leq \frac{\tilde{x}}{u(\tilde{x})}
$$

Therefore $(7),-\frac{x u^{\prime \prime}(x)}{u^{\prime}(x)}<1-\rho$, and (62) are necessary and sufficient for this equilibrium to exist.

\subsection{Effects of Government Debt in Asymmetric Equilibria}

In an asymmetric equilibrium, if we measure welfare as the sum of expected utilities across agents, then we need to take account of bad buyers as well as good ones, and we obtain

$$
W=\rho\left[u\left(x_{L}\right)-x_{L}\right]+\alpha(1-\rho)\left[u\left(x_{F}\right)-x_{F}\right],
$$

where $x_{L}$ and $x_{F}$ denote, respectively, consumption in limited information and full information meetings in the $D M$, and $W$ is strictly increasing in $x_{L}$ and $x_{F}$ for $x_{L} \leq \hat{x}$ and $x_{F}<x^{*}$.

We have two goals in this subsection. The first is to determine how the trading of government debt affects exchange and welfare for given $\alpha$. In other words, given an economy with a particular fraction of defaulting buyers in the population, how will the existence of government debt affect what is consumed in limited-information and full-information DM meetings? Our second goal is to determine the effects of trading in government debt on the existence of particular asymmetric equilibria. Does government debt encourage or discourage default? 
First, for given $\alpha$, compare the properties of the equilibrium (equilibria) that exists (exist) without government debt, and with government debt, in alternative regions of the parameter space. Let $x_{L N}$ and $x_{F N}$ denote consumption in limited-information and full-information meetings, respectively, in an asymmetric equilibrium without government debt. Similarly, $x_{L D}$ and $x_{F D}$ are consumption quantities in the $D M$ when government debt is traded.

Proposition 6 If $\beta \geq \frac{x^{*}}{\alpha(1-\rho) u\left(x^{*}\right)+[1-\alpha(1-\rho)] x^{*}}$, then $x_{L N}<x_{L D}=x^{*}$ and $x_{F N} \leq x_{F D}$. Welfare is higher with government debt than without it.

Proof. From (56) an asymmetric equilibrium with government debt exists in which the incentive constraint does not bind, so $x_{L D}=x_{F D}=x^{*}$. If (40) holds, then an asymmetric equilibrium without government debt exists in which $x_{L N}=\hat{x}$ and $x_{F N}=x^{*}$, so $x_{L N}<x_{L D}$ and $x_{F N}=x_{F D}$, and welfare is higher in the equilibrium with government debt. If (44) and (45) hold, then an asymmetric equilibrium without government debt exists in which $x_{L N}=\hat{x}$ and $x_{F N}<x^{*}$. Therefore, $x_{L N}<x_{L D}$ and $x_{F N}<x_{F D}$ in this case, and welfare is higher in the equilibrium with government debt. Finally, if (47) holds, then an equilibrium without government debt exists in which $x_{L N}<\hat{x}$ and $x_{F N}<x^{*}$. Therefore $x_{L N}<x_{L D}$ and $x_{F N}<x_{F D}$ in this case, and welfare is higher in the equilibrium with government debt.

Proposition 7 If $\beta \leq \frac{\tilde{x}}{u(\tilde{x})}$ and $\beta<\frac{\frac{\hat{x}}{\alpha}}{(1-\rho) u\left(\frac{\hat{x}}{\alpha}\right)}$, then $x_{L N}<x_{L D}, x_{F N}=x_{F D}$, and welfare is higher with government debt than without it.

Proof. From (62), an equilibrium exists with government debt in which there is a binding incentive constraint, where $x=x_{L D}=x_{F D}$ solves (6). From (47), an equilibrium also exists without government debt where $x=x_{F N}$ also solves (47), so $x_{F D}=x_{F N}$. But in the equilibrium without government debt, $x_{L N}=\alpha x_{F N}=\alpha x_{F D}=\alpha x_{L D}<x_{L D}$, as both incentive constraints bind in the equilibrium without government debt.

Figure 3 shows the subdivision of the parameter space, according to which asymmetric equilibria exist, with and without government debt. First, Proposition 5 deals with regions 1, 2, and 3 in Figure 3, where an asymmetric equilibrium with government debt exists in which the incentive constraint does not bind. In region 1, there exists an equilibrium without government debt in which neither incentive constraint binds. In region 2 , there exist two equilibria without government debt; in one of these equilibria neither incentive constraint binds, and in the other both incentive constraints are binding. In region 3, there exists an equilibrium with no government debt where both incentive constraints bind. In regions 1,2 , and 3 , the equilibrium with government debt dominates any equilibrium without government debt that exists.

[Figure 3 here.]

Second, Proposition 6 deals with region 12 in Figure 3. In that subset of the parameter space, an equilibrium without government debt exists in which 
the incentive constraint binds, and bad buyers choose autarky rather than defaulting. This equilibrium dominates the equilibrium without government debt in which both incentive constraints bind, which also exists in region 12.

In Propositions 5 and 6, we have shown that there exist subsets of the parameter space for which issuing government debt will improve matters in asymmetric equilibria, for given $\alpha$. First (Proposition 5), for any $\alpha$ with $0<\alpha<$ 1 , there is a subset of the parameter space in which there exists an equilibrium with government bonds for which the incentive constraint does not bind, and in which there is more exchange in the $D M$, and higher welfare, than in any asymmetric equilibrium without government bonds that exists in that subset. Second (Proposition 6), for any $\alpha$ with $0<\alpha<1$, there is a subset of the parameter space in which there exists an equilibrium with government debt for which the incentive constraint binds, in which there exists an equilibrium without government debt in which both incentive constraints bind, and in which there is less exchange in the $D M$ and therefore lower welfare in the equilibrium without government debt.

In regions 4 through 11 in Figure 3, it is more difficult to draw conclusions, though we know that, by continuity, the introduction of government debt must be welfare improving for sufficiently large $\alpha$. This follows from the fact that government debt always improves matters in symmetric equilibria - essentially the special case where $\alpha=1$.

In the equilibrium with government bonds in which the incentive constraint does not bind (regions 1, 2, and 3 of Figure 3), the welfare improvement from trade in government bonds does not result from effects on default behavior. Indeed, if such an equilibrium exists for given $\alpha$, then there exists an equilibrium without government bonds for the same $\alpha$. The key welfare-improving effect is that introducing government bonds solves the adverse selection problem in limited-information meetings in the $D M$. With government bonds, good buyers are no longer charged a default premium in limited-information exchange, and more goods are traded. However, in the equilibrium with government bonds, good buyers suffer because bad buyers always default on their taxes. Thus, good buyers have to bear the entire burden of paying the net interest on the government debt.

In an asymmetric equilibrium with government debt in which the incentive constraint binds and bad buyers choose autarky $(\hat{v}=0)$, in region 12 of Figure 3 , government debt improves the allocation for two reasons. First, as we outlined for the case where the incentive constraint does not bind, government debt solves the adverse selection problem in limited information meetings in the DM. Second, in region 12 of Figure 3, bad buyers do not default in equilibrium, but instead choose autarky. Therefore, the behavior of bad buyers has no effect on good buyers.

Next, government debt can act to mitigate default in that it can kill some undesirable asymmetric equilibria. Note in particular that, without government bonds, an asymmetric equilibrium exists for any $\alpha \in(0,1)$ and $(\beta, \rho) \in(0,1) \times$ $(0,1)$. However, from $(56),(58),(60)$, and $(62)$, with government bonds, there is a subset of the parameter space where an asymmetric equilibrium does not 
exist, for given $\alpha$, where parameters satisfy

$$
\rho<1+\frac{x u^{\prime \prime}(x)}{u^{\prime}(x)}
$$

and

$$
\frac{\tilde{x}}{u(\tilde{x})}<\beta \leq \frac{\tilde{x}}{\alpha(1-\rho)[u(\tilde{x})-\tilde{x}]+\tilde{x} u^{\prime}(\tilde{x})}
$$

This subset comprises regions 8, 9, and 10 in Figure 3. Note further that this subset expands as $\alpha$ decreases, so government debt more successfully does away with default the more severe the default problem is.

Note that we are not saying that government debt is useful because it leads to nonexistence of equilibrium. Indeed, we showed that, with government debt, a symmetric equilibrium always exists (i.e. $\alpha=1$ ). Another way to state the idea in the previous paragraph is that there are some regions of the parameter space for which the introduction of government debt implies that an asymmetric equilibrium exists only if $\alpha$ is sufficiently large. Thus, government debt eliminates some equilibria with large numbers of defaulters.

\section{Discussion}

The problem in this model that government debt mitigates or solves is an endogenous one. There always exists an equilibrium under global punishments in which the allocation is efficient. In such an equilibrium, government debt is irrelevant - the economy is Ricardian. However, there are many equilibria, and we have focused here on ones that we think are particularly interesting.

First, in symmetric equilibria with individual punishments in which default does not occur in equilibrium, the existence of government debt matters for the equilibrium allocation, and the optimal provision of such debt will in general increase the quantity of exchange and economic welfare. This can be interpreted as a role for government debt as collateral. Government debt acts to make private credit work better, as the government can use the threat of seizure of government debt as an incentive device in the tax system. For the government in our model, the incentives work in a straightforward manner, as anyone who knowingly cooperates with a defaulter is subject to confiscation, with the government taking back its own liabilities.

In practice, private arrangements that give similar incentives appear to be relatively costly to set up. For example, central counterparties $(\mathrm{CCPs})^{7}$ rely on punishment mechanisms similar to the ones involving government debt in our model. Typically, a defaulter on a CCP transaction ceases to be a member of the CCP, and all of its assets at the CCP are seized. ${ }^{8}$ In practice it is very

\footnotetext{
${ }^{7} \mathrm{~A}$ central counterparty (CCP) interposes itself between counterparties to financial contracts traded in one or more markets, becoming the buyer to every seller and the seller to every buyer. See http://www.bis.org/publ/cpss61.pdf

${ }^{8}$ In the case of the bankruptcy filing by the bank holding company unit of Lehman Brothers in September 2008, the National Security Clearing Corporation stopped clearing further trades
} 
costly for anyone to trade with a counterparty who defaulted. Since a defaulter is prevented from accessing central clearing services, then that entity can only trade if the securities are also cleared bilaterally. However, knowing that a counterparty defaulted, any clearing bank will require a very high price for the service.

In our model, without government debt, credit is limited by the potential for a borrower to default on a private credit arrangement. But when there is enough government debt to displace private credit, secured credit (or, what is equivalent here, the use of government debt in exchange) is limited by the potential for agents to default on their tax liabilities, where taxes are necessary to finance the net interest on the government debt. Effectively, the potential burden of default is transferred from the private sector to the government. But, in spite of the fact that the government is no better at collecting on its debts than are private sector lenders, this transfer increases welfare. This is because government debt acts to alter the incentives of borrowers who default (on tax liabilities rather than private liabilities). Two effects are responsible for lowering the value of being a defaulter. First, the cost of acquiring government debt to trade is costly. Second, asset holding are not anonymous, which permits punishment to be enforced when a defaulter is caught. Effectively the off-equilibrium punishment from defaulting is higher with government debt than without it.

Second, in asymmetric equilibria with individual punishments, some borrowers always default on their debts because they have nothing to lose from defaulting - their behavior is bad because they are treated badly when caught, but just often enough they don't get caught. In such equilibria, there are additional welfare-enhancing effects of government debt. Government debt can solve an adverse selection problem in private credit market arrangements subject to limited information. Effectively government debt permits all credit to be secured, which can support equilibria with more exchange and higher welfare. As well, government debt can eliminate equilibria with high default rates. Thus, government debt can mitigate default, and can enhance the ability of private sector agents to defend themselves against default, thus increasing the volume of credit.

The model illustrates two roles for collateral, which are somewhat related. The first role is related to a borrower's incentive to default. When government debt is available for use in exchange, or to post as collateral in private credit contracts, default can become more costly for borrowers, which makes lending more attractive. The second role is related to the terms on which a lender is willing to extend credit when it is difficult to screen borrowers. When some borrowers always default, and buyers use government debt in exchange, the borrower's type is irrelevant to the seller, and the existence of collateral allows lending to proceed on better terms, with a lower interest rate and larger loan quantity. Government debt solves the adverse selection problem by making the contract information-insensitive ${ }^{9}$ and thus reducing the friction in exchange.

for the broker-dealer unit of Lehman, which had not declared bankruptcy yet, agreeing to simply clear the positions Lehman was winding down.

${ }^{9}$ See Dang, Gorton and Holmstrom (2009). 
The interpretation of the private decentralized exchange in the model as collateralized credit, with government debt serving as collateral, is consistent with how markets in repurchase agreements (repos) work in practice, and with some features of the recent financial crisis. A repo is a bilateral agreement between a short-term lender (e.g. a money market mutual fund) and a borrower (e.g. e.g. a dealer) involving the sale and repurchase of securities. This is essentially a loan where the securities serve as collateral. ${ }^{10}$. Government debt, among other liquid assets including asset-backed securities, is an important collateral asset in the repo market which, in times of turmoil, turned out to be very valuable. During the recent financial crisis, the quality of collateral, as measured by repo haircuts, ${ }^{11}$ differed substantially among Treasury securities, agency securities, asset-backed securities issued by government-sponsored enterprises (GSEs), other kinds of asset-backed securities, and corporate bonds (see for example Martin et al. 2012). Treasury securities, agency securities, and mortgage-backed securities issued by GSEs traded with very low haircuts during the period 2008-2010. ${ }^{12}$ Furthermore, the vast majority of securities used as collateral for repo transactions are government securities. In 2008 only $25 \%$ of repo collateral was non-government and non-agency securities, while from 2009 this share has dropped to $15-18 \%$ and remained stable. ${ }^{13}$

Thus, consistent with our model, in times of credit market dysfunction such as the recent financial crisis, government-related securities are relatively more valuable as collateral. In our model government debt acts to free up the credit arrangements between buyers and sellers, so that welfare increases. In the model, liquid government securities work on the intensive margin; the loan that the seller grants the buyer is larger when it is secured by good collateral. A larger loan is (weakly) welfare improving ${ }^{14}$.

We have shown here that it is not the limited commitment friction alone that is the ultimate source of a role for government debt in credit markets, since efficient equilibria exist in which government debt is irrelevant. What makes government debt useful is limited commitment in conjunction with a poor endogenous choice of punishment for default, and the existence of defaulting debtors.

\section{Conclusion}

In this model, government debt can act to discourage default, and to reduce the quantity of equilibrium default. Effectively, government debt can be interpreted as playing a role as collateral in private credit contracts, and the fact that - like good collateral - government debt can be easily seized, helps to discipline agents

\footnotetext{
${ }^{10}$ See Garbade (2006).

${ }^{11}$ The haircut is the difference between the value of an asset and the value of the loan that is secured by the asset as collateral. See Martin et al. (2010).

${ }^{12}$ Consistent with our model, the government debt in countries with a weak power to tax, for example Italy, tends to be less useful as collateral than U.S. government debt, for example.

${ }^{13}$ See Krishnamurthy et al. (2013) and New York Federal Reserve Bank (2014a, 2014b).

${ }^{14} \mathrm{It}$ is strictly welfare improving when the incentive constraint is binding.
} 
who potentially or actually default on private or public debts. The model uses ideas from the monetary theory literature, in which memory and recordkeeping play a critical role in giving government liquidity a role in exchange. Government debt matters in this model because of limited memory, in conjunction with weak punishments for default. This creates the possibility that agents can borrow even if they have defaulted in the past, and in that context the economy is non-Ricardian - government debt matters.

A novelty in this limited commitment model is that default can occur in equilibrium, which opens up interesting possibilities for future work. For example, this model could be extended to consider the coexistence of secured and unsecured private credit arrangements. As well, it is possible to use this model environment to analyze endogenous fluctuations in which the aggregate default rate varies over time. Such a model would be useful for studying financial panics.

\section{References}

Aiyagari, S.R. and McGrattan, E. 1998. "The Optimum Quantity of Debt," Journal of Monetary Economics 42, 447-469.

Aiyagari, S.R. and Williamson, S. 2000. "Money and Dynamic Credit Arrangements with Private Information," Journal of Economic Theory 91, 248279 .

Andolfatto, D. 2011. "The Simple Analytics of Money and Credit in a Quasilinear Environment," working paper 2011-038A, St. Louis Federal Reserve Bank.

Athreya, K. 2002. "Welfare Implications of the Bankruptcy Reform Act of 1999," Journal of Monetary Economics 49, 1567-1595.

Cho, I. and Kreps, D. 1987. "Signaling Games and Stable Equilibria," Quarterly Journal of Economics 102, 179-221.

Corbae, D., Chatterjee, S., Nakajima, M., and Rios-Rull, J. (2007). "A Quantitative Theory of Unsecured Consumer Credit with Risk of Default," Econometrica 75, 1525-1589.

Dang, T., Gorton, G., and Holmstrom, B. 2009. "Opacity and the Optimality of Debt for Liquidity Provision," working paper, Yale University.

Diamond, P. 1965. "National Debt in a Neoclassical Growth Model," American Economic Review 55, 1126-1150.

Freeman, S. 1996. "The Payments System, Liquidity, and Rediscounting," American Economic Review 86, 1126-1138.

Garbade, K. 2006. "The Evolution of Repo Contracting Conventions in the 1980s," Federal Reserve Bank of New York Economic Policy Review 12, $27-42$. 
Gu, C., Mattesini, F., and Wright, R. 2013. "Money and Credit Redux," working paper.

Gu, C., and Wright, R. 2011. "Credit Cycles," forthcoming, Journal of Political Economy.

Holmstrom, B. and Tirole, J. 1998. "Private and Public Supply of Liquidity," Journal of Political Economy 106, 1-40.

Kehoe, T. and Levine, D. 1993. "Debt-Constrained Asset Markets," Review of Economics Studies 60, 865-888.

Kiyotaki, N., and Moore, J. 2008. "Liquidity, Business Cycles, and Monetary Policy," working paper, Edinburgh University, London School of Economics, and Princeton University.

Kocherlakota, N. 1996. "Implications of Efficient Risk Sharing without Commitment," Review of Economic Studies, 63, 595-609.

Kocherlakota, N. 1998. "Money is Memory," Journal of Economic Theory 81, 232-251.

Kocherlakota, N. 2003. "Societal Benefits of Illiquid Bonds," Journal of Economic Theory 108, 179-193.

Kocherlakota, N. 2008. "Exploding Bubbles in a Macroeconomic Model," working paper, Federal Reserve Bank of Minneapolis.

Krishnamurthy, A., Nagel, S., and Orlov, D. 2014. "Sizing Up Repo," Journal of Finance, forthcoming.

Lagos, R. and Rocheteau, G. 2008. "Money and Capital as Competing Media of Exchange," Journal of Economic Theory 142, 247-258.

Lagos, R. and Wright, R. 2005. "A Unified Framework for Monetary Theory and Policy Analysis," Journal of Political Economy 113, 463-484.

Lester, B., Postlewaite, A., and Wright, R. 2012. "Information, Liquidity, Asset Prices and Monetary Policy," Review of Economic Studies, forthcoming.

Martin, A., Skeie, D., and von Thadden, E. 2012. "Repo Runs," Staff Report \#444, Federal Reserve Bank of New York.

Mailath, G., Okuno-Fujiwara, M., and Postlewaite, A. 1993. "Belief-Based Refinements in Signalling Games," Journal of Economic Theory 60, 241276 .

New York Federal Reserve Bank, 2014a. "Tri-Party Repo Statistical Data," http://www.newyorkfed.org/banking/tpr_infr_reform_data.html 
New York Federal Reserve Bank, 2014b. "Primary Dealer Statistics", http://www.newyorkfed.org/markets/gsds/search.html

Rocheteau, G. 2008. "Money and Competing Assets Under Private Information," working paper \#08-02, Cleveland Federal Reserve Bank.

Rocheteau, G. 2011. "On the Coexistence of Money and Higher-Return Assets and its Social Role," working paper, University of California-Irvine.

Rocheteau, G. and Wright, R. 2005. "Money in Search Equilibrium, in Competitive Equilibrium, and in Competitive Search Equilibrium," Econometrica $73,175-202$.

Sanches, D., and Williamson, S. 2010. "Money and Credit with Limited Commitment and Theft," Journal of Economic Theory 145, 1525-1549.

Townsend, R. 1979. "Optimal Contracts and Competitive Markets with Costly State Verification," Journal of Economic Theory 21, 265-293.

Williamson, S. 2012. "Liquidity, Financial Intermediation, and Monetary Policy in a New Monetarist Model," American Economic Review, forthcoming.

Woodford, M. 1990. "Public Debt as Private Liquidity," American Economic Review 80, 382-388. 
Figure 1: Time Line

Govt. bonds issued.

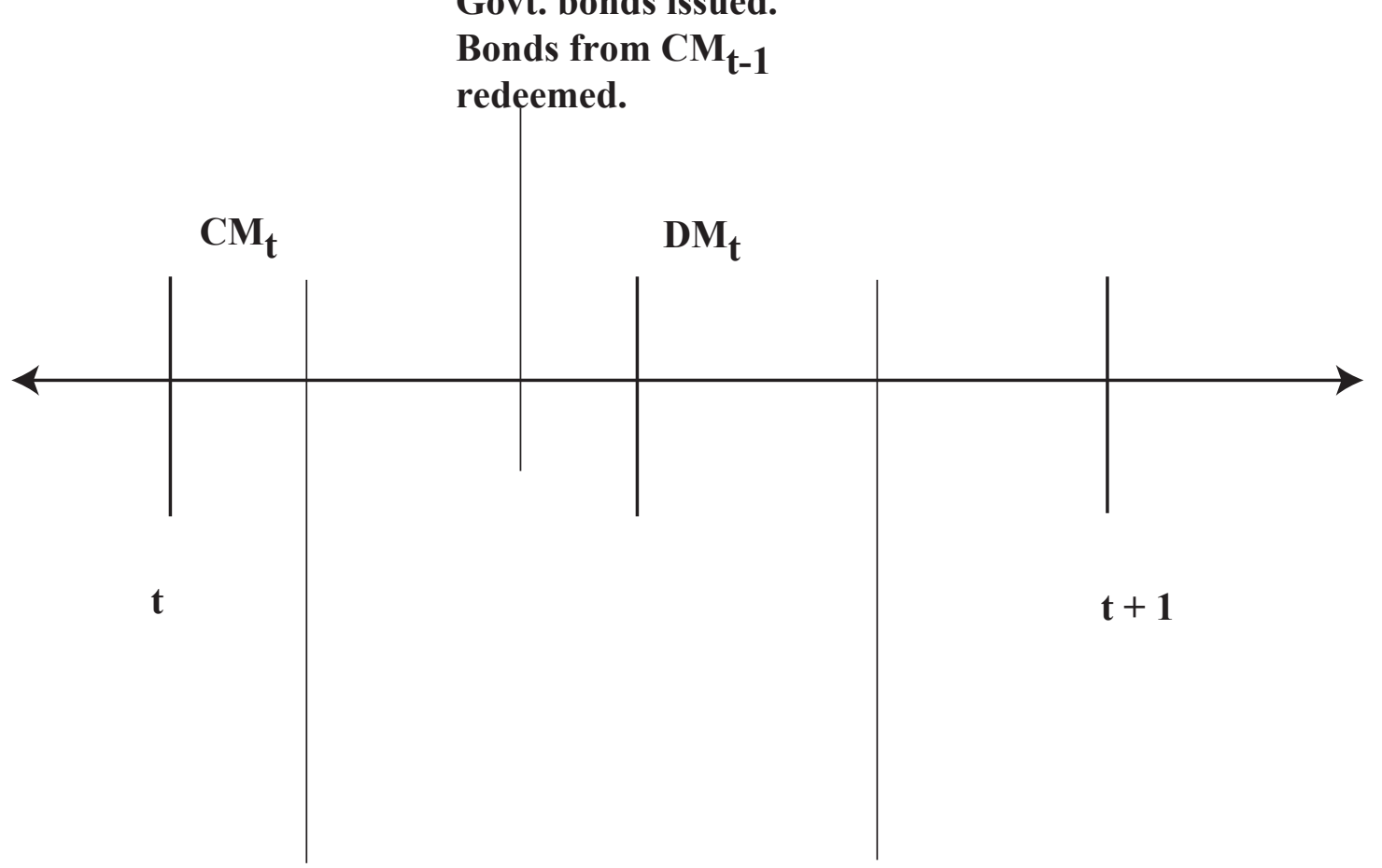

Debts from period $\mathrm{DM}_{\mathrm{t}-1}$

Random matching. settled and taxes paid

Exchange of personal

IOUs and government debt for goods. 
Figure 2: Symmetric Equilibria with Individual Punishments

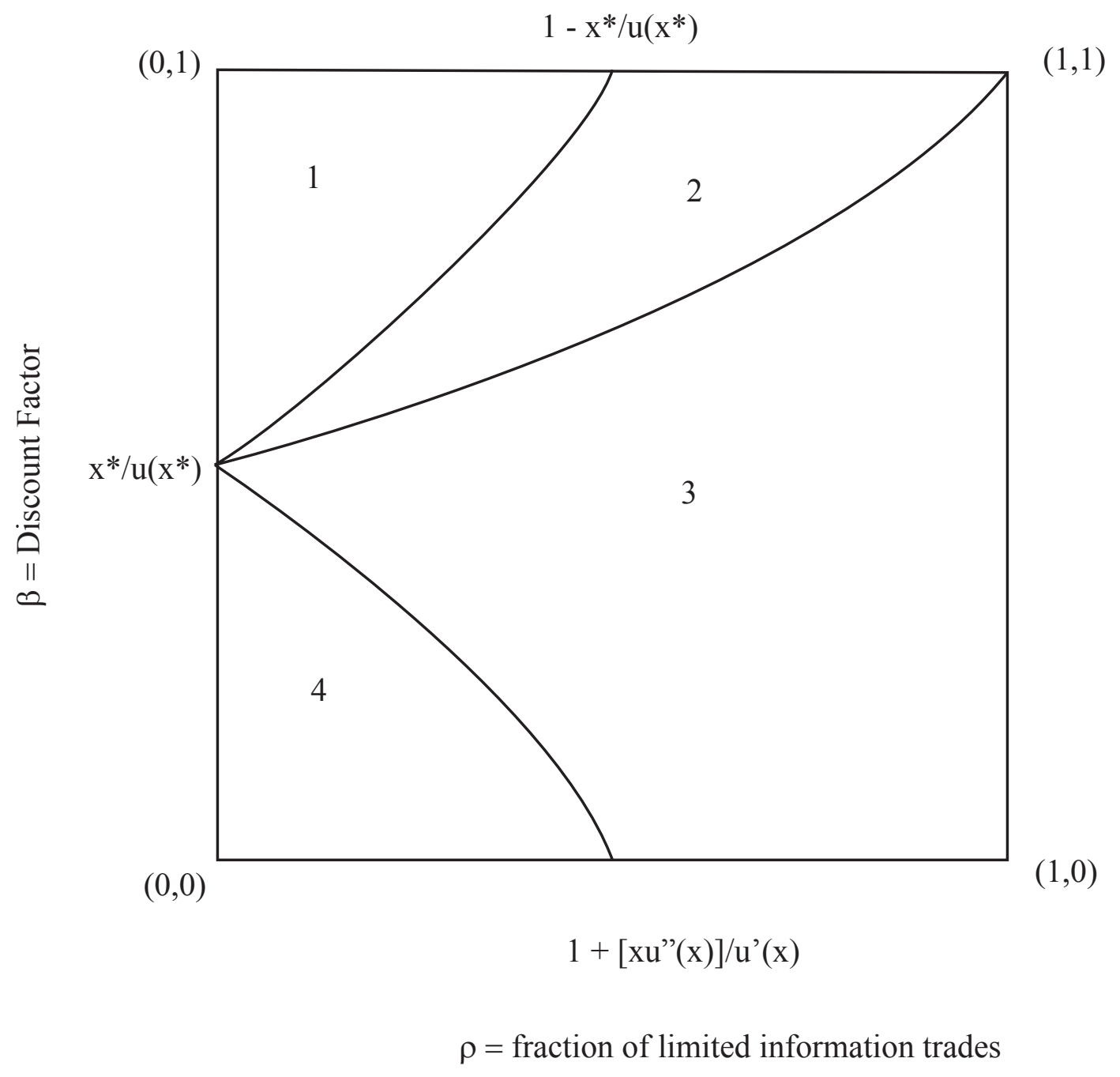


Figure 3: Symmetric Equilibria with Individual Punishments

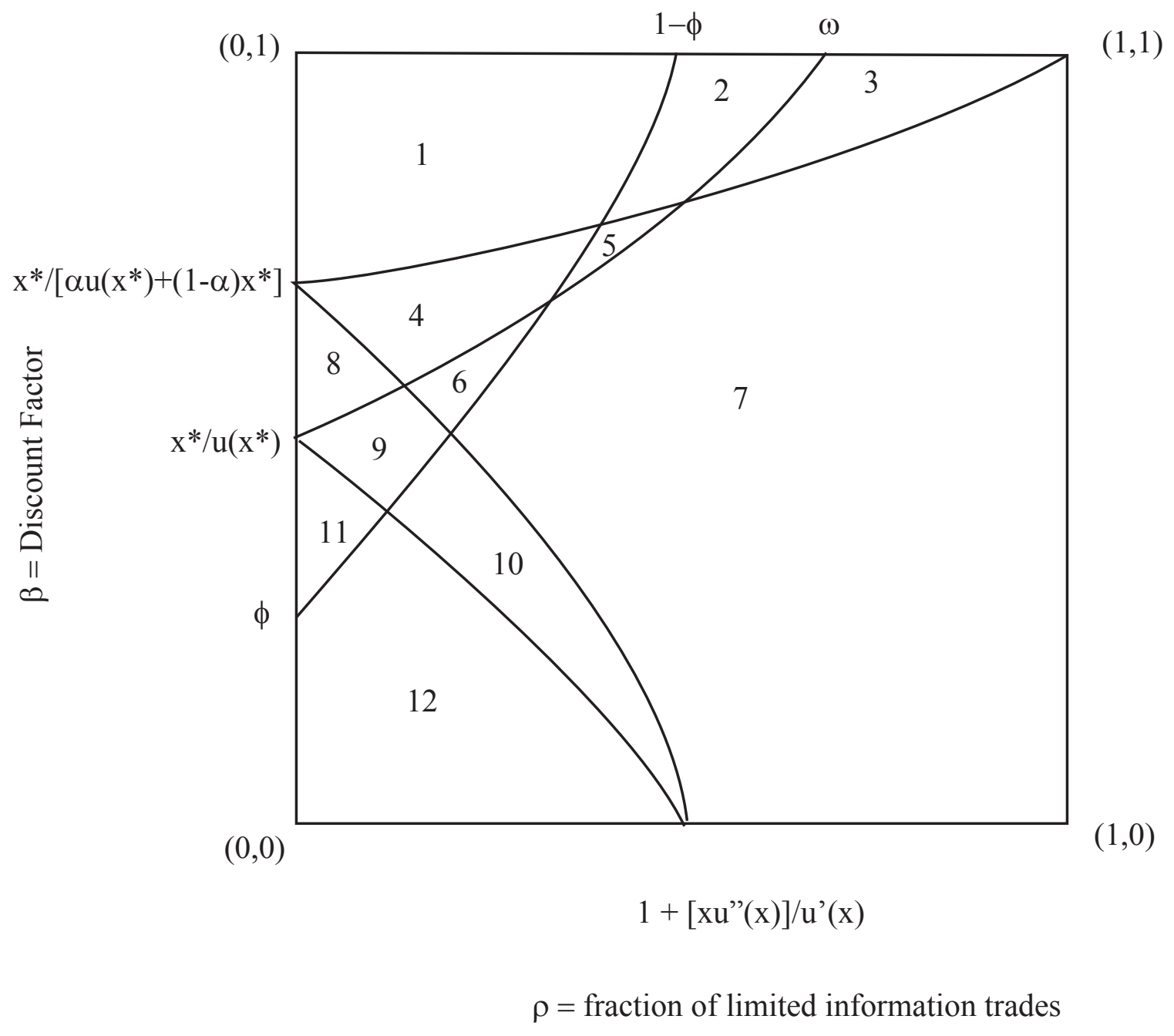

